\title{
Effects of Gonadectomy and androgen Supplementation on Attention in Male Rats
}

Ryan Taylor Johnson

College of William \& Mary - Arts \& Sciences

Follow this and additional works at: https://scholarworks.wm.edu/etd

Part of the Cognitive Psychology Commons, and the Experimental Analysis of Behavior Commons

\section{Recommended Citation}

Johnson, Ryan Taylor, "Effects of Gonadectomy and androgen Supplementation on Attention in Male Rats" (2005). Dissertations, Theses, and Masters Projects. Paper 1539626501.

https://dx.doi.org/doi:10.21220/s2-z53x-3608

This Thesis is brought to you for free and open access by the Theses, Dissertations, \& Master Projects at W\&M ScholarWorks. It has been accepted for inclusion in Dissertations, Theses, and Masters Projects by an authorized administrator of W\&M ScholarWorks. For more information, please contact scholarworks@wm.edu. 


\title{
EFFECTS OF GONADECTOMY AND ANDROGEN SUPPLEMENTATION ON
}

\section{ATTENTION IN MALE RATS}

\author{
A Thesis \\ Presented to \\ The Faculty of the Department of Psychology \\ The College of William and Mary in Virginia \\ In Partial Fulfillment \\ Of the Requirements for the Degree of
}

Master of Arts

by

Ryan Taylor Johnson

2005 


\section{APPROVAL SHEET}

This thesis is submitted in partial fulfillment of the requirements for the degree of

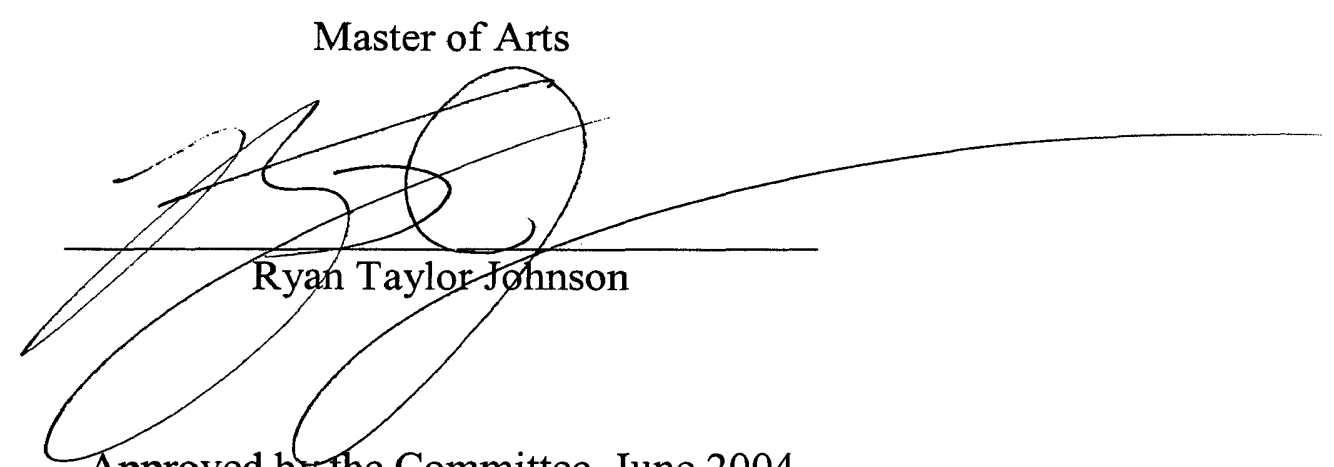

Approved by the Committee, June 2004
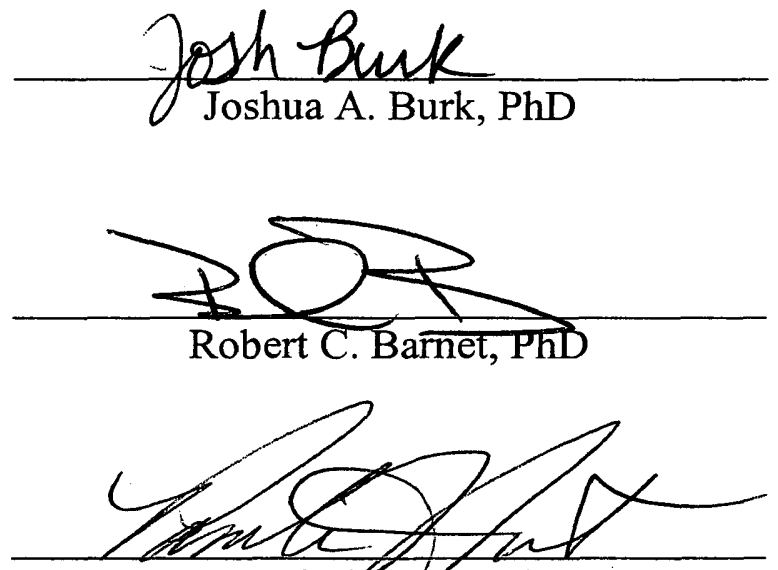

Pamela S. Hent, $\mathrm{PhD}$ 


\section{TABLE OF CONTENTS}

\section{Page}

Acknowledgements

iv

List of Tables

v

List of Figures

vi

Abstract

vii

Introduction

2

Method

Experiment1

Experiment2

Results

Experiment1

Experiment2

Discussion

32

References

48

Vita

60 


\section{ACKNOWLEDGEMENTS}

The author would like to thank Dr. Joshua Burk for his extraordinary mentoring and patience. His counsel during the past two years has been vital to the development of the author as a researcher and scholar. The author would also like to thank Dr. Lee Kirkpatrick for his year of mentoring and continued support.

Thank you to Dr. Robert Barnet and Dr. Pamela Hunt for their careful review of the manuscript and enthusiastic instruction. Additionally, the author would like to thank Allison Cameron and Juliet Aiken for their help in collecting data and Dr. Paul Heideman for his counsel concerning surgical procedures. Finally, the author would like to express his appreciation to the subjects of these studies, without which this research would not be possible. 


\section{LIST OF TABLES}

Table

Page

1. Pre-surgical Performance.

40

2. Post-surgical Performance. 


\section{LIST OF FIGURES}

Figure $\quad$ Page

1. Average weights by group. 43

2. Omissions for First Day of Distractor Sessions. 44

3. Correct Rejection Percentage for Each Dose of DHT. 45

4. Lever Press Latencies for Each Dose of DHT. 46

5. Correct Rejection Percentage for Each Dose of T. 47

6. PC Latencies for Each Dose of T. 48 


\begin{abstract}
Recently, the brain itself has been characterized as a steroidogenic organ, capable of producing a variety of hormones, including androgens. Androgens interact with several neural systems including the glutamatergic, GABAergic, and cholinergic systems. Presumably through these actions, androgens have been linked to enhancements of mnemonic processes, most commonly spatial working memory. However, little information is available examining the effects of androgens on attentional processing. The present experiments examined the effects of gonadectomy (Experiment 1) and acute supplementation, with aromatizeable or nonaromatizeable androgens (Experiment 2), on performance in a two-lever, nonspatial attention task that requires discrimination of visual signals and nonsignals and is known to be dependent upon the integrity of the basal forebrain corticopetal cholinergic system. In Experiment 1 Male Long Evans rats were trained in the attention task and then were gonadectomized (GDX) or received sham gonadectomy (Sham) as adults. Upon returning to the attention task, task difficulty was augmented using a visual distractor, and briefer inter-trial intervals. Also the effects of administering the muscarinic receptor antagonist scopolamine $(0,0.1 \mathrm{mg} / \mathrm{kg}$ and 0.2 $\mathrm{mg} / \mathrm{kg}$, IP) were tested. GDX and Sham animals performed similarly across all manipulations, with the exception of increased omissions by GDX animals on the first two sessions with a visual distractor. In Experiment 2 rats were trained to perform the attention task and then administered testosterone $(0,0.1 \mathrm{mg} / \mathrm{kg}$, and $0.5 \mathrm{mg} / \mathrm{kg}$, IP) or dihydrotestosterone $(0,0.1 \mathrm{mg} / \mathrm{kg}$, and $0.5 \mathrm{mg} / \mathrm{kg}, \mathrm{IP})$ while performing the baseline version of the attention task and in the presence of a visual distractor. Administration of testosterone $(0.5 \mathrm{mg} / \mathrm{kg})$ decreased animals' ability to correctly identify non-signals on both versions of the task compared to vehicle-treated sessions. Dihydrotestosterone (0.5 $\mathrm{mg} / \mathrm{kg}$ ) produced a similar decrease in correct detection of non-signals during visual distractor sessions only. The present results suggest that androgen-induced improvements in spatial working memory might not be due to enhancement of attentional processing. Furthermore, androgens do not appear to be necessary for normal attentional processing, but administration of androgens can adversely affect attentional performance.
\end{abstract}


EFFECTS OF GONADECTOMY AND ANDROGEN SUPPLEMENTATION ON ATTENTION IN MALE RATS 


\section{Introduction}

Research continues to provide evidence that several brain regions including nuclei of the preoptic area, the posterior dorsal medial amygdala, and parts of the hypothalamus are sexually dimorphic and that these differences are the result of a complex system of hormonal influences on neural structure (Morris, Jordan, \& Breedlove, 2004; Swaab \& Fliers 1985; Allen \& Gorski 1991). These influences, though most pronounced at key points in development, continues throughout the life of the organism as demonstrated by the production of hormones within the central nervous system, termed "neurohormones", in adult animals (reviewed in Compagnone \& Mellon, 2000). In addition, research has revealed sex differences to varying degrees in both nonhuman (Williams \& Meck, 1991) and human (Voyer, Voyer, \& Bryden, 1995; Asture, Ortiz, \& Sutherland, 1998) animals in several cognitive and affective operations including verbal and episodic memory (Herlitz, Airaksinen, \& Nordstrom, 1999), spatial memory (Lewin, Wolgers, \& Heritz, 2001), anxiety (Bradley \& Wygant, 1998; Frick, Burlingame, Arters, \& Berger-Sweeney, 2000) and motor impulsivity (Jentsch \& Taylor, 2003). This variation in cognitive functioning is suspected to be the phenotypic result of hormonal impact on brain structure, though the details of timing, action, and breadth of the influence are presently unresolved.

However unclear the details, within the past decade it has become undeniable that hormones do play a role in the regulation of both brain structure and cognitive functioning throughout life. One of the most described, and perhaps the most powerful, areas of cognitive-hormone interactions are the processes and regions involved in storage and recollection of information, or memory. However, there is a relative absence of research examining the role hormones may play in initial attentional processing. The 
present study arose out of a need for research examining what role hormones may play in the cognitive operation of attention and examined whether gonadectomy or androgen supplementation influences attention in adult rats.

\section{Androgens and Brain Structure}

Though both sexes produce estrogens and androgens, much of the research surrounding neuroendocrinology has been concerned primarily with estrogens. One of the chief causes of this focus is the discovery that hormone replacement therapy in post menopausal women protected patients from neurological disease and produced modest cognitive improvements (Fillit et al., 1986). This almost serendipitous finding has led to continued exploration of the benefits of estrogens in the central nervous system and investigations of how female sex steroids confer these profits. Indeed, estrogens have been shown to have neuroprotective effects (Goodman, Bruce, Cheng, \& Mattson, 1996; Weaver, Marek, Park-Chung, Tam, \& Farb, 1997), and appear to be related to cognitive functioning (Phillips \& Sherwin, 1992a; Phillips \& Sherwin, 1992b). However, the primary circulating estrogen, estradiol $\left(\mathrm{E}^{2}\right)$, is created in the body through aromatization of testosterone (T), an androgen. This sex hormone paradox has developed an interesting literature of its own, and research continues to examine the details of where and how the aromatase enzyme acts (Celotti, Negri-Cesi, \& Poletti, 1997; Balthazart, Foidart, \& Harada, 1990).

With a substantial amount of research already examining estrogen and neural structure, and the rising rates of elderly men seeking androgen replacement therapy, attention is now being directed toward the role of androgens in modulating neural development and maintaining neural health. Androgens are particularly interesting; 
especially when one considers that their presence en masse in the brain is the exception in development. In humans and many other species, the female phenotype is the default. It is only due to the presence of the $\mathrm{Y}$ chromosome, more specifically the 250 base pair sequence referred to as the Sry gene, which through unclear mechanisms alters DNA to promote the development of testes from the undifferentiated gonads. Once the testes have developed, production of androgens increases to a level at which the steroids begin exerting powerful influences on neural development (Morris, Jordan \& Breedlove, 2004). Androgens are primarily produced in the testes, but are also produced in small quantities in the adrenal glands and in glial cells in the CNS (Zwain \& Yen, 1999). The production of androgens by the testes is regulated through a complex system of feedback mechanisms in the hypothalamus-pituitary-gonad (HPG) axis. Upon stimulation of this axis, the anterior hypothalamus-preoptic area sends gonadotropin-releasing hormone $(\mathrm{GnRH})$ to the anterior pituitary which releases Luteinizing hormone (LH). LH, upon reaching the testes stimulates the Leydig cells to produce androgens. Testosterone, which is the primary androgen in men, reaches target tissue through systemic circulation. Once inside the CNS and upon reaching a neuron, $\mathrm{T}$ crosses the cell membrane and may bind to intracellular androgen receptors (AR) directly, be converted into dihydrotestosterone (DHT) through $5 \alpha$-reductase which binds to AR 5 times as readily as T, or be converted through aromatase into $\mathrm{E}^{2}$ and bind to estrogen receptors. Though both $\mathrm{T}$ and DHT produce similar effects by binding to AR, DHT is not capable of being converted to $\mathrm{E}^{2}$ and hence when compared to T, DHT acts solely as an androgen. Once bound the AR and its attached ligand enter the nucleus where it exerts effects through the regulation of gene transcription and subsequent protein production (Plassart-Schiess, \& Baulieu, 2001; 
reviewed in Kang, Tsai, Chang, \& Huang, 2003). These genomic actions are thought to be responsible for the organizational effects of androgens in the brain. However, androgens are also capable of acting at the membrane to produce a variety of effects through interaction with several neural systems.

In the glutamatergic system, neuroactive steroids, including dihydroepiandrosterone (DHEA) a potent androgen, have been shown to modulate NMDA receptor activity (Compagnone, Mellon, 1998; Mellon, Griffin, \& Compagnone, 2001). DHEA is considered a positive modulator of NMDA receptors (reviewed in Plassart-Schiess, \& Baulieu, 2001). More specifically, Compagnone and Mellon (1998) demonstrated that administration of DHEA into cultured mouse neurons increased the intra-cellular concentrations of calcium without the administration of NMDA or potassium chloride. These findings have been replicated in chick neuronal cultures (Fahey, Lindquist, Pritchard, \& Miller, 1995). Compagnone and Mellon (1998) also showed that DHEA greatly amplifies NMDA-induced increases in cellular activity and that this mediation was reduced in a dose-dependant manner by NMDA receptor antagonists. The authors concluded that DHEA was acting directly at the NMDA receptor to modulate activity and receptor subunit plasticity. Androgens have also been reported as playing an important role in mediating apoptosis using ischemic models of neurodegeneration, and as NMDA excitotoxicity is one of the primary causes of neural damage after cerebral ischemia it is suspected that androgens achieve their neuroprotection through interactions with the glutamatergic system (Rhodes, \& Frye, 2004).

Similar findings have been demonstrated for androgens and the GABAergic system. 
When methyltestosterone, a 17-alpha-aklylation of testosterone, which differs from the base hormone only in affinity for the aromatase and 5-alpha-reductase enzymes, was administered it produced increases in current amplitudes slightly below that of traditional benzodiazepines (Yang, Jones, \& Henderson, 2002). Interestingly the benzodiazepine altered times for cellular deactivation, desensitization, and recovery from desensitization but the androgen did not. Subsequent experiments revealed that the co-administration of benzodiazepines and methyltestosterone had additive effects on cellular activation and that administration of a benzodiazepine receptor anatgonist did not inhibit the actions of the methyltestosterone. Researchers have concluded that androgens are acting on GABA receptors through a novel binding site, further indicating the extent to which androgens act as unique and important neural modulators (Yang, Jones, \& Henderson, 2002; Harrison, Simmonds, and Majewska, 1984).

Additionally, research examining the expression of GABA receptor subunits in the medial amygdala, medial preoptic area, and the ventromedial nucleus of the hypothalamus in mice found that administration of methyltestosterone decreased expression of $\alpha$ and $\gamma$ subunits of GABA receptors. Interestingly the effect was dependent upon dose, sex, and age of the animal (McIntyre, Porter, \& Henderson, 2002). More specifically, pubertal female mice demonstrated mRNA changes with both the high and moderate dose while male mice were only affected as adults and only by the high dose of androgens (McIntyre, Porter, \& Henderson, 2002). These findings reveal that though androgens are acting on the GABAergic system, there actions are linked to developmental timing and vary across sex. Continued research is needed to explore the intricacy of this interaction, as the GABAergic and glutamatergic systems are tied to 
several other neural circuits and thus androgens' influence on these may indirectly link androgens to a multitude of other neural systems.

Evidence for androgens' impact beyond the major excitatory and inhibitory systems of the CNS is already being produced. Androgens have been tied to changes in the cholinergic system, which is itself closely linked to attention (Sarter \& Bruno, 1997). Using male rats, Nakamura, Fujita, and Kawata (2002) found that gonadectomy produced significant decreases in choline acetyltransferase, the enzyme responsible for binding acetate and choline together to form acetylcholine, in multiple areas of the basal forebrain. This detriment was not seen in sham-gonadectomized animals or in animals gonadectomized and implanted with silastic capsules containing testosterone propionate.

Additional research has examined actions of androgens on specific cholinergic receptors. For example, in rats, stimulation of the muscarinic receptors in the medial preoptic area is involved in facilitating sexual behavior (Hull, et al., 1988), and administration of the muscarinic receptor antagonist scopolamine leads to suppression of sexual behavior (Retana-Marquez, Dominguez, \& Velazquez-Moctezuma, 1993). Interestingly, in gonadectomized rats exhibiting an absence of sexual behavior, peripheral administration of oxotremorine, a specific cholinergic receptor agonist, does not reestablish sexual behavior. However, the coadministration of testosterone and oxotremorine fully restored sexual behavior. This effect was greater than that of $\mathrm{T}$ alone and suggests that the facilitative effect of cholinergic stimulation on sexual behavior requires the presence of androgens (Retana-Marquez \& Velazquez-Moctezuma, 1993). Androgens and the cholinergic system are also linked in the development of Alzheimer's disease. Ishunina and colleagues (2002) examined this link and found that AR staining in 
basal forebrain cholinergic neurons was significantly reduced in Alzheimer's disease patient compared to age-matched controls (Ishunina, Fisser, \& Swaab, 2002).

Through their interactions with other neural systems alone, androgens can be identified as an important component of brain function. However, many of the interesting extensive effects can be found at a structural level, by examining the role of androgens in specific brain nuclei. The presence of androgens can be identified by localization of AR and by neuronal production of the enzymes responsible for the metabolism of androgens from their precursors. Using these methods, AR and androgenic enzymes have been found throughout the adult brain of several animals (reviewed in Compagnone \& Mellon, 2000; Mellon, Griffin, \& Compagnone, 2001; Meethal \& Atwood, 2005). However, particular areas appear to be more impacted by androgens than others and these highly androgen-reactive areas include several structures known to be closely tied to mnemonic and attention related processes (Ishunina, Fisser, \& Swaab, 2002; Bimonte-Nelson, Singleton, Nelson, Eckman, Barber, Scott, Granholm, 2003; Adler, Vescovo, Robinson, \& Kritzer, 1999; Naghdi, Majlessi, \& Bozorgmehr, 2004).

For instance, androgens have been found to exhibit actions in the cortex. Control of the rate limiting enzyme for catecholamine synthesis in all layers of the dorsal anterior cingulate has been found to be at least partially influenced by androgens (Adler, Vescovo, Robinson, \& Kritzer 1999), and counts of choline-acetyltransferase positive cells in layers II and III in both the posterior parietal and anterior cingulate cortices have been found to be reduced by castration and this reduction is tempered by supplementation with testosterone implants (Nakamura, Fujita, and Kawata, 2002). 
Within the limbic system, the hippocampus is recognized to play a crucial role in many cognitive processes; especially those involved with memory, and has been found to be very responsive to hormonal changes. The density of dendritic spine synapses in the CA1 region of the hippocampus increased substantially in gonadectomized male and female rats treated with DHEA (MacLusky, Hajszan, \& Leranth, 2004). Importantly this effect was still present in animals treated with an aromatase inhibitor, blocking conversion of androgens into estrogen, and when treated with the non-aromatizeable androgen DHT, indicating that the effects were not due to biosynthesis of estrogen (MacLusky, Hajszan, \& Leranth, 2004). Quite perplexing were the findings that the androgen receptor antagonist, flutamide, also produced increased dendritic spine density, and when co-administered with androgens the effects were additive rather than inhibitory (MacLusky, Hajszan, \& Leranth, 2004). Additionally, androgens have also been shown to alter nerve growth factor levels in the hippocampus with androgen treatment resulting in lower hippocampal levels of nerve growth factor (Bimonte-Nelson, Singleton, Hunter, Price, Moore, \& Granholm, 2003). These results seem to contradict the findings by MacLusky et al. (2004) relating androgens positively to increased dendritic density in the hippocampus, however Bimonte-Nelson et al. administered testosterone which is readily converted to estrogen, and the authors speculate that it may be the ratio of testosterone to estrogen or the aromatase enzyme itself that is responsible for their observed effects (Bimonte-Nelson, Singleton, Hunter, Price, Moore, \& Granholm, 2003). Furthermore, Nakamura, Fujita, and Kawata (2002) found that 4 weeks after gonadectomy, male rats showed significant decreased cell counts of choline acetyltransferase positive neurons in the medial septum area of the basal forebrain. This change in basal forebrain neural 
structure was not present in sham animals or gonadectomized animals implanted with testosterone supplements.

Further research has revealed androgens mediating and being mediated by ictal activity (Rhodes \& Frye, 2004) and anxiety (Frye \& Edinger, 2004) through processes within the hippocampus. The resulting picture is one of an intimate and Byzantine system linking androgens to hippocampal structure and function. Taken together, the current literature demonstrates that the influence of androgens seems to be exerted in multiple areas related to cognitive processes, especially those areas related to memory and attention. However, it is useful to review current findings relating androgens to memory, learning, and other cognitive processes before exploring the possible link between androgens and attention.

\section{Androgens and Behavior}

Androgens have a relatively controversial history of being associated with various behaviors including aggression (for a meta-analysis of findings in humans see Book, Starzyk, \& Quinsey, 2001) and social dominance (reviewed in Mazur \& Booth, 1998). Additionally, continued research demonstrates the scope of androgens' influence in cognitive and affective measures.

Gonadectomy of male mice has been shown to decrease open field activity, and this deficit is alleviated by supplementation with androgens (Adler, Vescovo, Robinson, Kritzer, 1999). In related findings, injection of testosterone significantly reduced anxiety, as measured by an elevated plus maze in male mice. This effect was independent of overall motor activity and occurred in a dose dependent manner (Aikey, Nyby, Anmuth, \& James 2002). This anxiolytic effect is suspected to be mediated through androgen and 
metabolites in the hippocampus. Specifically, anxiety was increased in animals given infusions of indomethacin, a dehydrogenase inhibitor, into the CA1 region of the hippocampus (Frye \& Edinger, 2004). Androgens' anxiolytic effects may also be related to their analgesic effects (Frye \& Seliga, 2001) as androgens have been shown to produce place preferences in rats and are suspected to produce positive hedonic and reinforcing effects similarly to known analgesics (Rosellini, Svare, Rhodes, \& Frye, 2001).

Beyond their anxiolytic and analgesic properties, androgens have continuously been associated with changes in mnemonic functioning. In a recent study of patients undergoing androgen deprivation, cessation of treatment resulted in significant increases in scores on several cognitive assessments including the Cambridge Examination for Mental Disorders of the Elderly - Cognitive Battery Revised and word recall memory tasks (Almeida, Waterreus, Spry, Flicker, \& Martins, 2004).

In multiple measures of learning and memory, reduction of androgens in non-human animals has produced performance deficits. Using a radial-water maze, aged animals were found to produce more working and reference memory errors than young animals. When aged animals were treated with testosterone reference memory and working memory errors were reduced (Bimonte-Nelson, et al., 2003). Using the conditioned fear paradigm, with a period of 5 days between training and testing, gonadectomized animals exhibited less freezing following contextual fear conditioning, which is dependent upon the hippocampus, than intact animals (Edinger, Lee, \& Frye, 2004). Though not as robust, this effect was also found for fear conditioning dependent upon a cue rather than a context, an process, which requires the amygdala but not the hippocampus to be intact (Edinger, Lee, \& Frye, 2004). Thus, androgens appear to be involved in both brain 
regions associated with these two variations of the fear-conditioning task. In the inhibitory avoidance paradigm, gonadectomized males demonstrated increased cross-over latencies compared to intact and gonadectomized animals supplemented with testosterone, indicating impairments in long-term spatial memory (Edinger, Lee, \& Frye, 2004; Frye \& Seliga, 2001).

Spatial memory is perhaps the area of mnemonic functioning that has been examined most closely. In a double-blind study, healthy older men were supplemented with $15 \mathrm{mg}$ testosterone patches for 3 months. Using the familiar block design subtest of the Wechsler Adult Intelligence Scale-Revised (Weschler, 1958), testosterone treatment improved spatial cognition (Janowsky, Oviatt, \& Orwell, 1994). Assessing the acute actions of androgens on cognition, in another placebo-controlled double blind study adult women were given a single administration of sublingual testosterone or placebo. Each administration was followed four to five hours later by a 3-dimensional mental rotation - task (similar to the lock design subtest mentioned previously). After controlling for learning effects, and phase of menstrual-cycle, testosterone produced significant improvements in visuospatial ability (Aleman, Bronk, Kessels, Koppeschaar, \& van Honk, 2004).

Indirect, yet interesting support for the role of androgens in spatial memory comes from the study of testicular feminization mutant mice (TFM). TFM mice possess a defect in the androgen receptor gene, resulting in the presence of androgens but the absence of androgen receptors. Since this defect is X-linked, TFM males are completely androgen insensitive while TFM females, being heterozygous for the gene error are still capable of producing androgen receptors. As expected, this results in sex differences in spatial 
memory performance, with female TFM mice performing better in the Morris water maze than male TFM mice (Rizk, Robertson, \& Raber, 2005). The same study also utilized wild-type mice in the same behavioral test, and though the authors reported no statistics directly comparing the 2 types of mice, they did note that the TFM mice required an extra day of training to reach a performance level equal to that of the wild-type mice (Rizk, Robertson, \& Raber, 2005). Finally, utilizing a virtual version of the Morris water maze designed for humans, a recent study found that testosterone levels were positively correlated with performance during the last block of maze training (Driscoll, Hamilton, Yeo, Brooks, \& Sutherland, 2005). Thus, in both human and non-human animals, androgen levels have repeatedly been demonstrated to be linked to various cognitive processes, particularly those related to various types of memory. With this consistent demonstration of androgens affecting the storage and retrieval of information, it is perplexing that little is known about the actions of androgens as related to attending to information. Attention is a complex cognitive process, the biology of which has close ties or is affected in numerous neurological diseases such as Alzheimer's (Kasa, Rakonczay, Gulya, 1997; Lawrence, Sahakian, 1998; Gouras, Gross, Greenfield, Hai, Wang, \& Greengard, 1999), schizophrenia (Maruff, Hay, Malone, \& Currie, 1995) and of course, attention deficit hyperactivity disorder. Many of these diseases show modest to strong sex differences in occurrence and may be linked to changes in the hormonal milieu. Mechanisms of Attention

Definitions of attention as a functional construct have originated mostly from an information processing approach. Specifically, multiple input streams or stimuli impact the senses at any given moment, yet organisms are generally responsive to only a fraction 
of these stimuli (Pashler, 1993). The mediation of selecting stimuli for further processing is the fundamental role of the construct of attention (Pashler, 1993). Implications arising from the adoption of this perspective include attention being closely tied to mnemonic encoding and indeed, a review detailing the acknowledged features of attention includes a mnemonic aspect (Mirsky, Anthony, Duncan, Ahearn \& Kellam, 1991). However, the necessity of attention functions in learning and memory is unclear (Everitt \& Robbins, 1997).

Multiple descriptions of the anatomy responsible for mediating attention have included two distinct systems (Posner \& Peterson, 1990; reviewed in Sarter, Givens \& Bruno, 2001). Recruitment of attention can be viewed as originating in two directions via overlapping arrangements. Though the two systems' descriptions may cause them to appear as dichotomous, they represent functional conceptualizations of overlapping systems that in most cases work together to optimize attentional performance (Sarter, Givens \& Bruno, 2001). The bottom-up system describes attention as being mediated by the characteristics of the stimulus and its context (Treisman, Warren, \& Dykes, 1990) and is mediated by norandrenergic projections from the locus coeruleus terminating in the thalamus and basal forebrain (Sarter, Givens \& Bruno 2001). In contrast, top-down processes are best conceptualized as being responsible for knowledge-driven augmentation of neural attention processing and is involved in filtration of signal from noise and other aspects of signal detection (Sarter, Givens and Bruno, 2001).

Top-down functions are known to be dependent upon corticopetal projections from the basal forebrain to both retral and forward cortical regions (Everitt \& Robbins, 1997). Consequently multiple theories of the neural mechanisms mediating complex 
attention processes contain both anterior and posterior attention regions. Posner and Peterson (1990) conceptualized the posterior structure, which includes the parietal cortex, superior colliculus and thalamic pulvinar nucleus to be involved in spatial orientation and to orient the animal to the area where stimuli are presented (Posner \& Peterson, 1990). As would be expected, the posterior attention region overlaps with the known dorsal visual pathway and PET studies have confirmed this (Petersen, Fox, Miezin \& Raichle, 1988). The anterior attention system includes the prefrontal cortex and the anterior cingulate cortex and is involved in mediating knowledge driven detection of stimuli and information processing and is responsible for the ability to selectively attend and to sustain attention (Sarter, Givens, \& Bruno, 2001). The anterior system has been shown to mediate the functioning of the posterior system and associated sensory areas through a complex system of circuitry centered around the basal forebrain (Posner \& Peterson, 1990; Connor, 2004, Sarter, Bruno, \& Givens, 2001, Sarter \& Parikh, 2005).

\section{The Basal Forebrain and Cholinergic System}

The basal forebrain is a cluster of brain nuclei responsible for production and trafficking of most of the brain's acetylcholine. Interestingly, the basal forebrain is the most rostral of the neuromodulatory cortical input systems (Sarter, Hasselmo, Bruno \& Givens, 2005), and its cholinergic projections have extremely widespread distribution in cortical regions (Everitt \& Robbins, 1997). Details of the substructures and cholinergic projection pathways have been described (Mesulam, 1995). Specifically, neurons of the medial septum and the vertical limb of the diagonal band of Broca project to the hippocampus and are labeled $\mathrm{Ch} 1$ and $\mathrm{Ch} 2$. Projections from the horizontal nucleus of the diagonal band of Broca innervate the olfactory bulb and are labeled Ch3. Finally, 
projections from the nucleus basalis of Meynert (nbM) which is itself part of the substantia innominata, innervate widespread cortical regions and are labeled $\mathrm{Ch} 4$ (Mesulam, 1995). Through exploration of this Gordian system, research continues to substantiate the basal forebrain and cholinergic system's involvement in attentional processes (Sarter, Hasselmo, Bruno \& Givens, 2005).

For example, in relation to attending to stimuli, in the auditory cortex of rats, administration of acetylcholine ( $\mathrm{ACh}$ ) increased response to tones, an effect that was also achieved through stimulation of the basal forebrain (Ashe, McKenna \& Weinberger, 1989). In the visual cortex, neurons showing an activation bias in response to one direction of movement demonstrated an increase in this bias after $\mathrm{ACh}$ administration into the visual cortex (Murphy \& Sillito, 1991). Administration of cholinergic agonists has been shown to increase the somatosensory representation of a whisker in rats, and administration of cholinergic receptor antagonists result in drastic reduction of this cortical representation (Penschuck, Chen-Bee, Prakash \& Frostig, 2002). Thus cholinergic innervations of cortical sensory areas serve to increase the response of cortical neurons to sensory inputs and to initiate changes in cortical sensory maps, serving to optimize attention (Sarter, Hasselmo, Bruno \& Givens, 2005).

However, the neural circuitry of attention extends beyond cortical sensory areas, and assessment of the attention process in its entirety has been achieved through the development of tasks involving complex rule systems and variable stimuli (McGaughy \& Sarter, 1995; Robbins, Everitt, Marston, Wilkinson, Jones \& Page 1989). The Robbins et al. (1989) task requires animals to respond to a brief signal presented in an array of 5 possible locations. The McGaughy \& Sarter (1995) operant task requires animals to 
discriminate between signal and non-signal trials with variable inter-trial intervals and brief stimuli. Performance in the McGaughy and Sarter (1995) task has been shown to involve activation of anterior and posterior attention regions and to be highly reactive to lesions and pharmacological manipulations of the basal forebrain and cholinergic system (Sarter, Givens \& Bruno, 2001; Robbins, Everitt, Martson, Wilkinson, Jones \& Page, 1989; Kozak, Bruno \& Sarter, 2005). For example, lesions to the cholinergic cells of the nucleus basalis of meynert lead to performance deficits in the two lever operant attention task (McGaughy, Kaiser, \& Sarter, 1996) and administration of muscarinic receptor antagonists (scopolamine) has been shown to reduce detection of signals in the operant conditioning task (Bushnell, Oshiro \& Padnos, 1997). Interestingly, though detection of signals is affected, detection of non-signal events is not. Findings suggest that rule switching may be mediated in part by the GABAergic projections from the basal forebrain. Briefly, infusions of the selective cholinotoxin 192 IgG-saporin have been shown to decrease animals' ability to detect signal events (McGaughy, Kaiser \& Sarter, 1996). In contrast, lesions of basal forebrain GABAergic neurons by infusion of ibotenic acid results in impairments in detection of non-signals events but spares the animals ability to detect signal events (Burk \& Sarter, 2001). More concisely, the reduction of cholinergic activity impairs ability to detect signals, while the increase of cholinergic activity impairs the ability to detect non-signals. Additionally, manipulations of task difficulty such as the incorporation of a visual distractor, substantially increase the demand on the attention system and have been shown to induce a corresponding increase in cholinergic activity (Gill, Sarter \& Givens, 2000). Collectively, these data confirm the necessity of the cholinergic system for the normal functioning of the attention system. 


\section{Androgens and Attention}

Continuing evidence points to the involvement of androgens in multiple aspects of CNS regulation and development. Production of androgens is widespread in the brain of adult animals and androgens have been shown to influence several of the major neurotransmitter systems, including the cholinergic system (Nakamura, Fujita, \& Kawata, 2002; Retana-Marquez, Dominguez, \& Velazquez-Moctezuma, 1993; Ishunina, Fisser, \& Swaab, 2002). Furthermore, androgens have been tied to changes in the structure of multiple brain regions associated with learning and memory and have been observed to enhance cognitive functioning, especially in tasks related to mnemonic functioning.

The neural circuitry regulating attentional processes has been carefully detailed, and a picture has emerged of a complex system highly dependent upon the integrity of the basal forebrain and its cholinergic projections to widespread cortical areas. Interestingly, androgens have been shown to influence many brain regions involved in attention, including the basal forebrain (Ishunina, Fisser, \& Swaab, 2002; Nakamura, Fujita, and Kawata, 2002), posterior parietal cortex (Nakamura, Fujita, and Kawata, 2002), and prefrontal cortex (Adler, Vescovo, Robinson, Kritzer, 1999) and have been shown to preserve neural machinery involved in the production of ACh Nakamura, Fujita, and Kawata, 2002). Yet, the connections between androgens and attention remain delitescent.

Considering the lack of precedence concerning this link, two questions would be of primary importance for the establishment of a foundation upon which further research may build: Are androgens necessary for attention processes and does supplementation of androgens improve attention processing? It is the goal of this study to begin the 
exploration of these questions which, given the importance of attention to other cognitive processes, may also provide insight as to how androgens provide their known cognitive enhancements. The previously described McGaughy \& Sarter (1995) operant task has been validated as capable of placing great demands on attentional processes, while remaining independent of non-attentional processes (Arnold, Burk, Hodgson, Sarter \& Bruno, 2002). The present experiments utilized this attention task to assess whether the systemic reduction of androgens impaired attention task performance and if the acute administration of androgens improved attentional functioning. Examination of the effects of systemic reduction of androgens was achieved through gonadectomy of task performing adult male rats and subsequent testing with augmented task difficulty including a visual distractor, short inter-trial intervals and impairment of the cholinergic system through administration of the cholinergic receptor antagonist scopolamine. The acute effects of androgens on attention were examined through injections of androgens administered immediately prior to task performance. However, given the confusion surrounding the role of estrogens as opposed to androgens in cognitive enhancement, supplementation of androgens included administration of an androgen that may be readily converted to estrogen (testosterone) as well as a non-aromatizeable androgen (dihydrotestosterone). Given the continued evidence, for positive cognitive enhancements provided by androgens, we predicted that after acquisition of the attention task, gonadectomized rats would exhibit an increased impairment in task performance when compared to non-gonadectomized rats. Furthermore we suspected that administration of androgens would improve task performance. However, given the overlap of androgens and estrogens cognitive enhancements properties, it was unclear to what extent 
testosterone and dihydrotestosterone would differentially improve attention task performance.

\section{Method}

\section{Experiment 1}

Subjects

Subjects were 22 male Long-Evans rats (Charles River Labs, Wilmington, Mass., USA) approximately 40 days old $(150-175 \mathrm{~g})$ at the start of the study. Animals were housed individually in hanging wire cages in a temperature and humidity-controlled vivarium on the College of William and Mary campus. Animals were kept on a 14/10 light dark cycle (lights on 0600 - 2000 hours) and all testing was conducted between $1100-1700$ hours. Animals were allowed access to food ad libitum. After an initial period of free water, access was available for 30 minutes after each session of training and as reward during behavioral training. Subjects were treated in accordance with the regulations of the Institutional Animal Care and Use Committee of the College of William and Mary.

Apparatus

Animals were trained in one of 12 chambers (Med Associates, Georgia, VT). Each chamber was enclosed in a sound-attenuating box equipped with a fan for ventilation and white noise. Within each chamber were two retractable levers positioned on either side of a water port. Three panel lights $(2.8 \mathrm{~W})$, one above each lever and one above the water port were located at the front of the chamber. A house light $(2.8 \mathrm{~W})$ was. located at the rear of the chamber. All data collection and program executions were controlled using MED-PC software (v. IV) on a PC clone. 


\section{Behavioral Training}

Animals were trained approximately six times a week in two groups, one session per day. Behavioral training consisted of three phases representing increasing levels of . task acquisition. Through all phases the house light was illuminated during the entire session. In the initial stage, animals were shaped to press either lever for reward $(0.1 \mathrm{ml}$ water). The levers were extended into the chamber at the start of the session and did not retract until the end of the session (approx. $45 \mathrm{mins}$ ). In order to prevent the development of a side bias, after 5 consecutive presses on the same lever, the animal would not receive a reward until pressing the opposite lever. After 3 consecutive sessions of 120 rewarded lever presses animals were advanced to the second phase of behavioral training.

The second stage of training introduced the following changes. Levers were extended into the chamber at the start of a trial and were retracted after a response. Animals were rewarded only for a correct response with the following parameters defining correct: if presented with a $1 \mathrm{~s}$ illumination of the central panel light, a correct response was a left lever press (hit). If presented with no signal a correct response was a right lever press (correct rejection). Failure to press either lever after $3 \mathrm{~s}$ was recorded as an omission. In this acquisition stage, if the animal responded incorrectly (false alarm, error on a non-signal trials or miss, error on a signal trial) the same trial was repeated. After 3 repetitions, if the animal did not respond correctly, a forced choice trial in which only the correct lever was extended for $90 \mathrm{~s}$ was introduced. In the case of a failed signal trial, the light was illuminated during the entire forced choice trial. The inter-trial interval (ITI) was $12 \pm 3 \mathrm{~s}$. Each session lasted approximately 35 minutes. After three 
consecutive sessions of greater than 70 percent hits and correct rejections the second phase was concluded and animals began the final phase of behavioral training.

The final phase of behavioral training removed correction trials, forced choice trials, reduced the inter-trial interval to $9 \pm 3 \mathrm{~s}$, and introduced variable signal lengths $(500,100$, and $25 \mathrm{~ms})$. Each training session consisted of 162 trials or 81 signal trials (27 at each signal length) and 81 non-signal trials. This form of the task was used for all subsequent testing with the exclusion of the task variations described in post-surgical testing and is subsequently referred to as the standard task. Behavioral acquisition and qualification for surgery was considered complete after 3 consecutive sessions of greater than 70 percent hits $(500 \mathrm{~ms})$ and correct rejections. Animals took approximately 3 months to reach this level of training.

\section{Behavioral Measures}

For each session, the total number of hits, misses, correct rejections, false alarms and omissions were recorded. Latencies to respond across trial type and latencies to enter the water port were collected in milliseconds. The percentage of hits $[100 *($ hits/(hits + misses)) $]$ and correct rejections [100*(correct rejections/(correct rejections+false alarms))] were also recorded. Data were collected for each animal for each session.

\section{Surgical Procedures}

After reaching criterion performance, half the animals were gonadectomized (GDX, $\mathrm{n}=11$ ) and half received sham gonadectomies (Sham, $\mathrm{n}=11$ ). Animals were approximately six months old at the time of surgery. All surgeries were performed in aseptic conditions under anesthesia composed of Xylazine $(6.0 \mathrm{mg} / \mathrm{kg}$, IP) and Ketamine $(90.0 \mathrm{mg} / \mathrm{kg}, \mathrm{IP})$, administered in a single injection. In both GDX and Sham groups, the 
surgery site was shaved and cleaned, and the scrotal sac and underlying tunica were incised. For the Sham group the incisions were then closed with wound clips and the surgical site was cleaned. For the GDX group, the cauda epididymidis, caput epididymidis, vas deferens and the testis were extracted. The vas deferens were ligated bilaterally and the testes removed. The vas deferens were reinserted into the scrotal sac and underlying membrane, the wounds were closed using wound clips, and the surgery sight was cleaned. All animals received a subcutaneous injection of ampicillin $(0.0025$ $\mathrm{mg} / \mathrm{kg}, \mathrm{SC}$ ) and allowed to regain consciousness under a heat lamp before being returned to their home cages. Animals were given free access to food and water and allowed to recover for 5 days. For the first 3 days of recovery acetaminophen $(2.7 \mathrm{mg} / \mathrm{ml})$ was mixed with the animals' water. After completion of testing, animals were euthanized by exposure to $\mathrm{CO}_{2}$ and the seminal vessels were removed. Vessels were emptied of fluid and weighed. Seminal vesicle weights have been repeatedly used as a reliable biological assay for androgen depletion (Heideman, Bierl, \& Galvez, 2000; Heideman, Bierl, and Sylvester, 2001).

\section{Testing and Behavioral Manipulations}

After 5 days of recovery from surgery animals were returned to the testing chambers. Animals were tested on the standard task for 20 sessions. Data from days 19 and 20 were collapsed and used as a baseline level of task performance. Reestablishment of baseline performance was defined as $\geq 2$ consecutive sessions of within $15 \%$ relative hits, within $10 \%$ correct rejections, and within 15 omissions of this three day aggregate.

Following the 20 sessions of the standard task, two separate task manipulations were introduced. First, the standard task was altered to include a visual distractor 
(flashing house light, $1 \mathrm{~s}$ on/1s off). The flashing house light timing was independent of normal session actions. Animals were returned to the standard task after 3 sessions with the distractor. Secondly, following reestablishment of baseline performance on the standard task, animals were tested for one session with a shorter inter-trial-interval $(6 \pm 3$ s).

\section{Pharmacological Manipulations}

After a reestablishment of baseline performance following the short inter-trialinterval session, animals received 3 injections: a low dose of scopolamine $(0.1 \mathrm{mg} / \mathrm{kg}, \mathrm{IP})$, a high dose of scopolamine $(0.2 \mathrm{mg} / \mathrm{kg}, \mathrm{IP})$, and saline vehicle $(1.0 \mathrm{mg} / \mathrm{kg}, \mathrm{IP})$. Scopolamine powder was weighed and dissolved in saline prior to dosing. Animals were injected with $1.0 \mathrm{ml} / \mathrm{kg}$ of solution. Injection sequence was counter-balanced and a return to baseline performance was achieved between each injection. To allow sufficient time for the onset of drug actions, all sessions in which animals received an injection included a 30 min dark adaptation period in the testing chamber before the start of the task.

Experiment 2

Subjects

Subjects were 19 male Long/Evans rats (Charles River Labs, Wilmington, Mass., USA) approximately 40 days old $(150-175 \mathrm{~g})$ at the start of the study. Animals were housed individually in hanging wire cages in a temperature and humidity-controlled vivarium on the College of William and Mary campus. Animals were kept on a 14/10 light dark cycle (lights on $0600-2000$ hours) and all testing was conducted between $1100-1700$ hours. Animals were allowed access to food ad libitum. After an initial 
period of free water, access was available for 30 minutes after each session of training and as reward during behavioral training. Subjects were treated in accordance with the regulations of the Institutional Animal Care and Use Committee of the College of William and Mary (IACUC).

\section{Apparatus and Behavioral Training}

The apparatus and training procedures were identical to those described in Experiment 1.

\section{Behavioral Measures}

Behavioral measures were identical to those described in Experiment 1.

\section{Procedure}

After 3 consecutive sessions of greater than 70 percent hits $(500 \mathrm{~ms})$ and correct rejections on the standard task, subjects were pseudo-randomly assigned to either a testosterone or dihydrotestosterone treatment condition. Subjects were trained on the standard task for an additional 3 sessions, which were aggregated and served as a measure of baseline performance. Androgens (testosterone propionate, Sigma USA; dihydrotestosterone, Spectrum Chemical MFG. Corp., USA) were suspended in an oil vehicle (vegetable oil) and administered IP in one of three doses: vehicle alone, 0.1 $\mathrm{mg} / \mathrm{kg}$, and $0.5 \mathrm{mg} / \mathrm{kg}$. Animals received T or DHT. All subjects received each of the three doses of androgen immediately prior to the standard task and the standard task with a visual distractor. Thus, each subject was tested under a total of six conditions: standard task/vehicle, standard task/low dose, standard task/high dose, distractor task/vehicle, distractor task/low dose, and distractor task/high dose. All conditions included a $20 \mathrm{~min}$ dark adaptation period. Condition order was counterbalanced and animals were required 
to achieve at least 2 sessions of baseline performance, as defined in Testing and Behavioral Manipulations, between conditions. Statistical Analysis

All statistical analyses were conducted using SPSS 12.0 software (SPSS, Chicago, IL). Percent hits at each signal duration, percent correct rejections, omissions, and latencies were analyzed using mixed-model analyses of variances (ANOVAs). The $p$ values for within-subjects factors are reported after correction with the Huynh-Felt procedure. Animals treated with T and DHT were analyzed separately.

Results

Experiment 1

Surgical Manipulation: Body and Seminal Vesicle Weights

Animals' weights were compared prior to surgery, and 10 days post surgery. Analysis shows that the two groups did not differ in body weight prior to surgery $[t(19)=$ $1.061, p=0.316]$ but post-surgery the GDX group continually weighed lessr than the Sham group $[t(19)=-14.621, p=0.000]$ (Fig. 1). Subjects vessels were weighed emptied of seminal fluid and analysis shows a significant difference in vessel weight between GDX and Sham animals, $t(19)=-14.62, p<0.001$; mean paired vessel weight \pm SEM: GDX: $0.114 \pm 0.006 \mathrm{~g}$; Sham: $0.766 \pm 0.047 \mathrm{~g}$. Thus, data support the conclusion that gonadectomy was properly conducted.

Presurgical Performance

Data were averaged across the 5 days prior to surgery. Analysis revealed that GDX and Sham groups did not differ significantly on attentional performance prior to surgery (Table 1). 


\section{Postsurgical performance}

Data were averaged across the 20 days of testing after the animals returned from surgery. Results show that the two groups' performances did not differ significantly (Table 2). To further investigate possible differences in group performance, the 20 days of testing post-surgery were divided into two groups of 10 days each. A repeated measures ANOVA including this grouping as a factor revealed a three way interaction [day $\mathrm{x}$ group (GDX vs. Sham) $\mathrm{x}$ signal duration, $F(2,40)=4.365, p=0.025$ ]. However, t-tests were unable to identify significant differences between GDX and Sham groups for any signal duration for the 10 day groupings. Similar analyses revealed no effects of day for any other factors.

\section{Distractor Performance}

Behavioral measures from the 2 days immediately prior to onset of the task manipulations were averaged and compared to the day of testing with the manipulation. In the case of the distracter this meant a comparison of baseline performance with three days of distracter presentation.

For percent hits a three way [group (GDX vs. Sham) $\mathrm{x}$ signal duration $\mathrm{x}$ distractor) ANOVA indicated expected main effect for signal duration $[F(2,40)=262.862, p=0.000$; 500ms: $74.56 \pm 2.37,100 \mathrm{~ms}: 54.88 \pm 1.88,25 \mathrm{~ms}: 28.80 \pm 3.08]$ and distractor $[F(3,60)=$ 23.127, $p=0.000$; standard task: $64.83 \pm 2.04$, distractor day1: $48.42 \pm 2.21$, distractor day2: 47.97 \pm 2.11 , distractor day3: $49.75 \pm 3.08$ ], but no effect for group. No interaction was seen for signal duration $\mathrm{x}$ group, distractor $\mathrm{x}$ group, or signal duration $\mathrm{x}$ day $\mathrm{x}$ group.

For correct rejections a 2 way (group $\mathrm{x}$ distractor) ANOVA indicated an expected main effect for distractor $[F(3,60)=12.895, p=0.000$; standard task: $88.54 \pm 1.3$, 
distractor day1: 78.83 \pm 1.93 , distractor day2: $82.81 \pm 2.09$, distractor day3: $84.41 \pm 2.16]$. No interactions with, or main effects for group were found.

For omissions a 2 way (group $\mathrm{x}$ distractor) ANOVA revealed an expected main effect for distractor $[F(3,60)=4.565, p=0.014$; standard task: $8.34 \pm 1.51$, distractor day 1 : 18.91 \pm 3.89 , distractor day2: $11.32 \pm 2.42$, distractor day3: $9.09 \pm 2.64]$. No interaction with group was found. However, analysis did reveal a main effect of group $[F(1,20)=$ $7.152, p=0.015]$ with the GDX group committing more omissions than the Sham group (Fig. 2).

No main effect of distractor, group, or interaction between group and distractor was found for response latencies. Distractor increased PC latencies $[F(3,57), p=0.002$; standard task: $566.6 \pm 38.1$, distractor day1: $734.1 \pm 84.1$, distractor day2: $495.6 \pm 42.3$, distractor day3: 782.4 \pm 71.9$]$, but did not interact with group, nor was a main effect of group present.

Reduced Inter-Trial Interval Performance

Shorter inter-trial intervals did not interact with percent hits, and no interactions with condition were found for percent hits on reduced inter-trial interval sessions. Correct rejections were significantly reduced by reduced inter-trial intervals $[F(1,20)=$ $7.124, p=0.015$; standard task: $89.31 \pm 1.34$, reduced inter-trial intervals: $85.10 \pm 2.13$ ], but no interaction with, or main effect of, group was found. Omissions were reduced by reduced inter-trial intervals $[F(1,20)=191.679, p=0.000$; standard task: $9.39 \pm 1.51$, reduced inter-trial intervals: $6.55 \pm 1.81]$, but no interaction with group was found. Reduced inter-trial intervals increased response latencies $[F(1,19), p=0.021$; standard 
task: $517.5 \pm 31.4$, reduced inter-trial intervals: $604.1 \pm 29.3$ ] but did not interact with group. No main effect of group was found for response latencies during reduced inter-trial interval sessions. Furthermore, no main effects or interactions were found for PC latencies during reduced inter-trial interval sessions.

Pharmacological Manipulation Performance

For all behavioral measures scores from vehicle sessions were compared to the sessions of low and high dose scopolamine administration. As expected, scopolamine administration significantly reduced percent hits $[F(2,38)=6.258, p=0.006$; saline: 66.29 \pm 2.43 , low dose: $60.19 \pm 2.31$, high dose: $55.22 \pm 3.39$ ], but did not interact with group. Paired samples t-test indicated a significant reduction of percent hits between saline and low dose scopolamine $[t(20)=2.20, p=0.039]$, saline and high dose scopolamine $[t(20)=2.96, p=0.008]$ but no difference between low and high doses. Furthermore, as anticipated, scopolamine administration did not significantly affect correct rejections. No effect for group was found with correct rejections. Additionally, scopolamine administration did not affect omissions, and no main effects or interactions condition were found for group on omissions. Scopolamine administration did not significantly affect response latencies or PC latencies in any manner.

\section{Experiment 2}

All behavioral measures scores from vehicle sessions were compared to the sessions of low and high dose androgen administration. In the case of latencies, all response latencies (hit, false alarm, correct rejection, and miss) were collapsed into single variable, "response latency". Latency to enter the water port (PC latency) remained separate. 


\section{Dihydrotestosterone Administration}

For percent hits, a 3 way (dose $\mathrm{x}$ distractor $\mathrm{x}$ signal duration) repeated measures ANOVA revealed the anticipated main effects of distractor $[F(1,8)=34.622, p=0.000]$ and of signal duration $[F(2,16)=149.275, p=.000]$. However, there was no main effect of dose, nor did dose interact with any other factors for percent hits.

For correct rejections, a 2 way (dose $\mathrm{x}$ distractor) repeated measures ANOVA revealed no main effect of dose. As expected, there was a main effect for distractor $[F(1,8)=42.443, p=0.000 ;$ standard task: 86.65 \pm 2.27 , distractor task: $74.34 \pm 3.77]$

Interesting, was the presence of a distractor $\mathrm{x}$ dose interaction $[F(2,16)=4.331, p=0.037]$ (Fig. 3). Briefly, paired samples t-test revealed a significant difference between vehicle and high dose DHT $[t(8)=2.647, p=0.029]$ for distractor sessions only.

A 2 way (dose $\mathrm{x}$ distractor) repeated measures ANOVA revealed no effect of dose on omissions and no interaction between dose and distractor.

DHT administration did not affect PC latencies either as a main effect or in an interaction with distractor. However, similar to its actions on correct rejections, DHT administration produced an interaction between dose and distractor $[F(2,16)=3.742, p=$ 0.046] for response latencies. Injections of DHT increased latencies during distractor sessions (Fig. 4) but not in the standard version of the task. No main effect of DHT administration was found.

\section{Testosterone Administration}

For hits, a 3 way (dose $\mathrm{x}$ distractor $\mathrm{x}$ signal duration) repeated measures ANOVA revealed the expected main effects of distractor $[F(1,8)=16.444, p=0.004$; standard task: $63.47 \pm 2.92$, distractor task: $55.32 \pm 2.86]$ and of signal duration $[F(2,16)=77.896, p=$ 
0.000]. However there was no main effect of dose or interactions between dose and any other factors.

A 2 way (dose $\mathrm{x}$ distractor) repeated measures ANOVA revealed no effect of dose on omissions. As expected there was a significant effect of distractor $[F(1,8)=8.522, p$ $=0.019$, standard task: $7.74 \pm 3.82$, distractor task: $5.41 \pm 3.15]$, but there was no interaction bètween dose and distractor.

Interestingly, a 2 way (dose $\mathrm{x}$ distractor) repeated measures ANOVA demonstrated a significant effect of dose for correct rejections $[F(2,16)=3.967, p=0.04]$ (Fig. 5). A paired samples t-test revealed significant differences between vehicle and high dose $[t(8)=2.462, p=0.039]$ and between low and high doses $[t(8)=2.482, p=$ 0.038]. More explicitly, administration of $0.5 \mathrm{mg} / \mathrm{kg}$ of $\mathrm{T}$ decreased correct rejections compared to vehicle or $0.1 \mathrm{mg} / \mathrm{kg}$ of $\mathrm{T}$. The difference between vehicle and the low dose was non-significant (Fig. 5). The expected effect of distractor was also present $[F(1,8)=$ 20.978, $p=0.002 ;$ standard task: $86.74 \pm 1.87$, distractor task: $77.84 \pm 2.97]$, but there was no interaction between dose and distractor. Though the interaction was non-significant, exploratory analysis revealed that significant differences between doses occurred only during distractor sessions $[t(8)=2.321, p=0.049$; vehicle/distractor sessions: $81.07 \pm 3.30$, high dose/distractor session: $77.93 \pm 4.03]$.

Response latency was not affected by dose, but was decreased by introduction of a distractor $[F(1,8)=168.032, p=0.036$; standard task: $56.93 \pm 4.57$, distractor task:

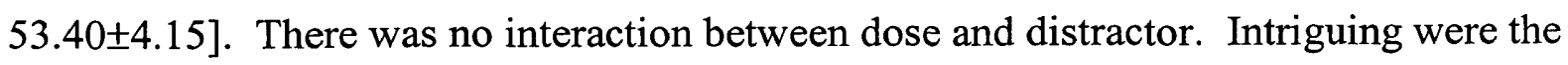
findings that dose significantly lowered PC latency $[F(2,16)=4.371, p=0.031]$. This 
effect did not interact with distractor. A paired samples t-test indicated that PC latency was significantly reduced by the low dose of $\mathrm{T}[t(8)=3.375, p=0.010]$ (Fig. 6).

\section{Discussion}

Given androgens continually demonstrated positive benefits on memory task performance, and the uncertain yet seemingly intuitive link between attention and memory, it was expected that androgens might enhance attention task performance. From a purely functional level, this expectation seems cohesive. However, from a more neurological approach the results obtained in this study, androgens impairing attention task performance, are in line with research detailing the interactions between androgens and other neural systems.

\section{Attention Processing and Androgen Deprivation}

Findings from experiment 1 suggest that androgens are not a necessary for normal attention task performance. By drastically impairing systemic androgen production, GDX animals were performing the attention task with circulating androgen levels well below that of Sham animals. However, a hypo-functioning androgen system seemed to have little effect on attention task performance.

Introduction of a visual distractor produced the expected deficits in attention performance, such as a reduction in hit percentage and reduction in correct rejection percentage but none of these deficits discriminated GDX from Sham animals. Latencies were initially increased by the augmentation in task difficulty but returned to more standard levels as distractor sessions continued. Again, this effect was similar in GDX and Sham groups. Only omissions changed differentially between the two groups as a result of introducing the distractor. 
Though GDX animals omitted more trials than Sham animals during the first 2 sessions with the visual distractor, this absence of performance is difficult to interpret. An increase in omissions does not fully translate to impaired attentional processes, and may be indications of more affective issues such as motivation. An assumption that increased task difficulty produced the lack of motivation, does not explain the lack of this effect during reduced inter-trail interval sessions. An alternative explanation might center on the introduction of novelty into the task environment. Introduction of a flashing house light might induce performance deficits merely as a result of altering the task environment. The explanation accounts for both the return to normal levels of omissions with further training and the absence of an omission effect during reduced inter-trial interval sessions and suggests that the GDX animals were more drastically affected by alteration of task environment. However, beyond this effect on omissions, evidence for the non-responsiveness of attentional functioning to reduced androgen levels is consistent.

The effects of reduced trial intervals were similar to those of a visual distractor. Percent correct rejections were reduced and omissions were slightly decreased. However, GDX and Sham groups responded similarly. Furthermore, and in support of the role of the cholinergic system in signal detection, the administration of scopolamine reduced percent hits, but did not impair correct rejections, omissions or latencies. Though this effect was not differentially predictive of group, it is important to note the specificity of response to cholinergic system manipulation.

Experiment 1 effectively demonstrated, that androgens are not a necessary part of the attention system. GDX and Sham animals exhibited no clear differences in attention task performance on the standard task. Furthermore, both groups demonstrated behavior 
that is consistent with pre-existing literature detailing the effects of various manipulations on attentional functioning. No manipulations including administration of a selective cholinergic antagonist differentiated the GDX and Sham groups for any of the strongest indicators of task performance. Thus, results suggest that androgens are not a necessary component of the neural circuitry mediating attention.

\section{Androgens as a Potential Cholinergic Agonist}

Experiment 2 presents interesting findings concerning androgens' actions in the CNS. To being, administration of both $\mathrm{T}$ and DHT reduced accuracy for detection of non-signal events. Importantly, this effect appears not to be simply a result of general task performance decline; percent hits, and omissions were not affected by androgen administration.

Detection of non-signal events is a function of cholinergic activity (Burk \& Sarter, 2001; Gill, Sarter \& Givens, 200). Androgens have been shown to have a facilitative effect for behaviors known to be dependant upon the cholinergic system (RetanaMarquez \& Velazquez-Moctezuma, 1997) and GDX has been demonstrated to reduce the amount of choline acetyltransferase in cortical areas and the medial septum (Nakamura, Fujita \& Kawata, 2002). Collectively this research suggests that the absence of androgens impairs cholinergic functioning and that behaviors dependent upon cholinergic activity can be facilitated by androgens. This leads to hypothesis that the reduction of accuracy for non-signal events seen in our data is the result of androgen supplementation amplifying the activity of the cholinergic system.

Furthermore, experiment 2 revealed that $\mathrm{T}$ and DHT administration similarly affected attention task performance. As noted above, $\mathrm{T}$ is converted to a number of 
metabolites, including estradiol and DHT. Considering the ongoing debate concerning whether estrogens or androgens produce cognitive benefits, the current findings support the contention that androgens are fully capable of altering neural activity without conversion to estrogen. However, discrimination between the cognitive benefits of androgens and current findings revealing attentional impairment with androgen administration is difficult to interpret.

\section{Consolidating Current Findings with Literature on Memory and Androgens}

One of the questions of interest is that if supplementation of androgens impairs aspects of attentional processes, how does supplementation of androgens improved mnemonic processes? Though the link is debated and unclear (for a synopsis of the debate see Sarter, Bruno \& Givens, 2003), attending to stimuli seems a necessary precursor to encoding them into memory. However, the nature of the deficit shown in this task may offer some explanation. The decrease in correct rejections is itself representative off an increase in false alarms or false positives, and as discussed above this has been demonstrated to be the behavioral manifestation of an increase in $\mathrm{ACh}$ efflux and is in effect an issue of over processing.

One possible explanation for this effect is the relative domain specificity of the types of task being utilized. Though exact dependence of each task to specific brain regions is very difficult to quantify, the attention task is dependant primarily upon the connections between the basal forebrain and cortical areas (references in Introduction). In contrast, the learning and memory tasks that androgens improve performance of are often associated with the hippocampus (Bimonte-Nelson, et al., 2003; Driscoll, Hamilton, Yeo, Brooks \& Sutherland, 2005; Edinger, Lee \& Frye, 2004). Though a complicated 
issue, research has demonstrated that impairment of the cholinergic system impairs new memory formation (Mohapel, Leanzab, Kokaiaa \& Lindavalla, 2005; D'Intino, et al., 2005; Rogers \& Kesner, 2003) and that androgens benefit hippocampal neural development (MacLusky, Hajszan \& Leranth, 2004; Mohapel, Leanzab, Kokaiaa \& Lindavalla, 2005). Thus androgens interact with the cholinergic system to produce augmentation of acetylcholine levels and work within the hippocampus to promote neuronal growth, and generate enhanced performance on learning and memory tasks dependent upon the hippocampus.

However, if androgens are producing a state of reduced accuracy in attention functioning, how does this result in an enhancement of mnemonic processes? The conflict is not easy to resolve and further research utilizing more comparable methodologies may clarify the issue. For example, the present studies involved acute administration of androgens. Furthermore, the most dramatic effects were found with the high dose $(0.5 \mathrm{mg} / \mathrm{kg})$ of androgens. Studies examining the mnemonic benefits of androgens frequently utilize sustained androgen release (Bimonte-Nelson et al., 2003; Edinger, Lee \& Frye, 2004; Frye \& Edinger, 2004) and perhaps acute administration would prove disruptive in these tasks as well.

Furthermore, the present studies' results are limited to an increase in false positives after acute androgen administration. Give the nature of the task and the neural circuitry involved, this is a very specific effect with a very specific assumption of what neural processes are behind it. However, direct comparison to learning and memory tasks is difficult given that false positives are not usually available as a response option. For example in the inhibitory avoidance and conditioned fear paradigms, a clear 
definition of a false positive seems elusive. In these instances, how would increased false positives be clearly distinguishable as detrimental to task performance?

Other learning and memory tasks such as the Morris water maze and radial mazes often lack a clearly identifiable single stimulus that the animal is identifying, missing, falsely identifying, or correctly rejecting. False alarms might be loosely construed as entering arms which no longer contain a reinforcer, yet research has demonstrated that androgens reduce these errors (Bimonte-Nelson et al., 2003). Thus at a functional level it is extremely difficult to ascertain how the detrimental effects of androgens on attentional functioning demonstrated in the present study correspond to their beneficial effects on more spatial learning and memory tasks.

\section{Implications for Androgens Interacting with the Cholinergic System}

Importantly, our data in a very indirect manner support the role of androgens as beneficial in the treatment of Alzheimer's disease (AD). Androgens and sex hormones in general have generated a continually increasing body of literature detailing their neuroprotecive effects (Bates, Harvey, Carruthers \& Martins, 2005; Ishunina, Fisser \& Swaab, 2002; Almeida, Waterreus, Spry, Flicker \& Martins, 2004). Investigations examining androgens positive actions at the neural level have been supplemented by behavioral research dependent upon a wide assortment of cognitive tasks, few of which are known to be closely tied to the neural system primarily affected by Alzheimer's disease. More specifically, $\mathrm{AD}$ can be accurately characterized as a disease of the cholinergic system (Kasa, Rakonczay \& Gulya, 1997; Lawrence \& Sahakian, 1998). Wide spread death of cholinergic neurons result in the cognitive impairments associated 
with the disease and the most effective treatments for $\mathrm{AD}$ center around amplification of ACh levels to compensate for this loss (Lawrence \& Sahakian, 1998).

The importance of the current findings is intensified by the neural specificity of the attention task. As mentioned previously, accuracy in the task is easily manipulated by changes in cholinergic efflux (Bushnell, Oshio, Padnos 1997; Turchi \& Sarter, 1997), with increased cholinergic activity being associated with over-processing and increased rates of false positives. Thus, the present results suggest that androgens are indeed interacting with the cholinergic system to produce increased ACh activity, signifying that androgens act not only as neuroprotectives, but may serve to augment or sustain cholinergic activity. Yet particulars surrounding how androgens are initiating these changes remain hidden.

Temporing the usefulness of the present findings in $\mathrm{AD}$ research is the limitation of the effect to the supplementation of androgens to supra-normal levels, while reduction of androgens did not cause animals to exhibit any behavior associated with altered cholinergic activity. Individuals at risk for $\mathrm{AD}$ are, given $\mathrm{AD}$ 's very strong association with aging, experiencing drastically reduced androgen levels, compared to that of young adults (reviewed in Meethal \& Atwood, 2005). Therefore, as far as serving as a model of andropause, experiment 1 is more appropriate. However, experiment 1 utilized healthy adult males who had been gonadectomized for less than 3 months by the time testing was complete. Andropause in humans is a steady decline of androgen levels over a large portion of the lifetime, and perhaps this continuous exposure to reduced androgen levels is essential for the onset of $\mathrm{AD}$ symptoms. Further examination of the effects of 
prolonged androgen deprivation and aging on attention task performance is necessary to clarify this interaction.

In conclusion, the present research indicates that the influence of androgens extends into multiple aspects of cognitive functioning including attention. Additionally, utilization of the attention task allowed the deduction that androgens actions seem to be occurring, at least in part, within the cholinergic system. Certainly further research is needed to clarify the nature of androgens involvement with the cholinergic system. Finally, it is becoming quite clear that androgens may have many more important roles in brain functioning than previously thought, and considering the astonishing distribution of steroidogenic enzymes found in the brain (Compagnone \& Mellon, 2000) it seems that exploration and understanding has just begun. Clearly, continued examination of the details of hormones interactions with cognitive processes is needed to fully utilize the potential benefits of hormones in fighting neurological diseases such as Alzheimer's and to elucidate the potential risk of extending the activity of a system so inexplicably tied to the development, operation and organization of the brain. 
TABLE 1

PRE-SURGICAL PERFORMANCE

\begin{tabular}{lrrrr}
\hline & \multicolumn{2}{c}{ GDX } & \multicolumn{2}{c}{ Sham } \\
\hline & Mean & Std. Error & Mean & Std. Error \\
Hits & 63.19 & 3.06 & 63.38 & 2.14 \\
Correct Rejections & 87.26 & 1.15 & 85.97 & 2.11 \\
Omissions & 11.84 & 3.83 & 9.23 & 1.62 \\
Response latencies (msec) & 473.12 & 28.05 & 499.32 & 28.14 \\
PC latencies (msec)* & 720.46 & 67.85 & 549.66 & 46.44 \\
\hline
\end{tabular}

* One outlier (greater than 3 standard deviations from group mean) was removed from the GDX group. 
TABLE 2

POST-SURGICAL PERFORMANCE

\begin{tabular}{lrrrr}
\hline & \multicolumn{2}{c}{ GDX } & \multicolumn{2}{c}{ Sham } \\
\hline & Mean & Std. Error & Mean & Std. Error \\
Hits & 65.26 & 2.91 & 63.65 & 2.32 \\
Correct Rejections & 85.92 & 1.18 & 88.04 & 1.83 \\
Omissions & 14.74 & 3.23 & 13.68 & 2.81 \\
Response latencies (msec) & 562.47 & 32.62 & 566.11 & 30.65 \\
PC latencies (msec) & 626.89 & 46.39 & 614.92 & 52.78 \\
\hline
\end{tabular}




\section{FIGURE 1}

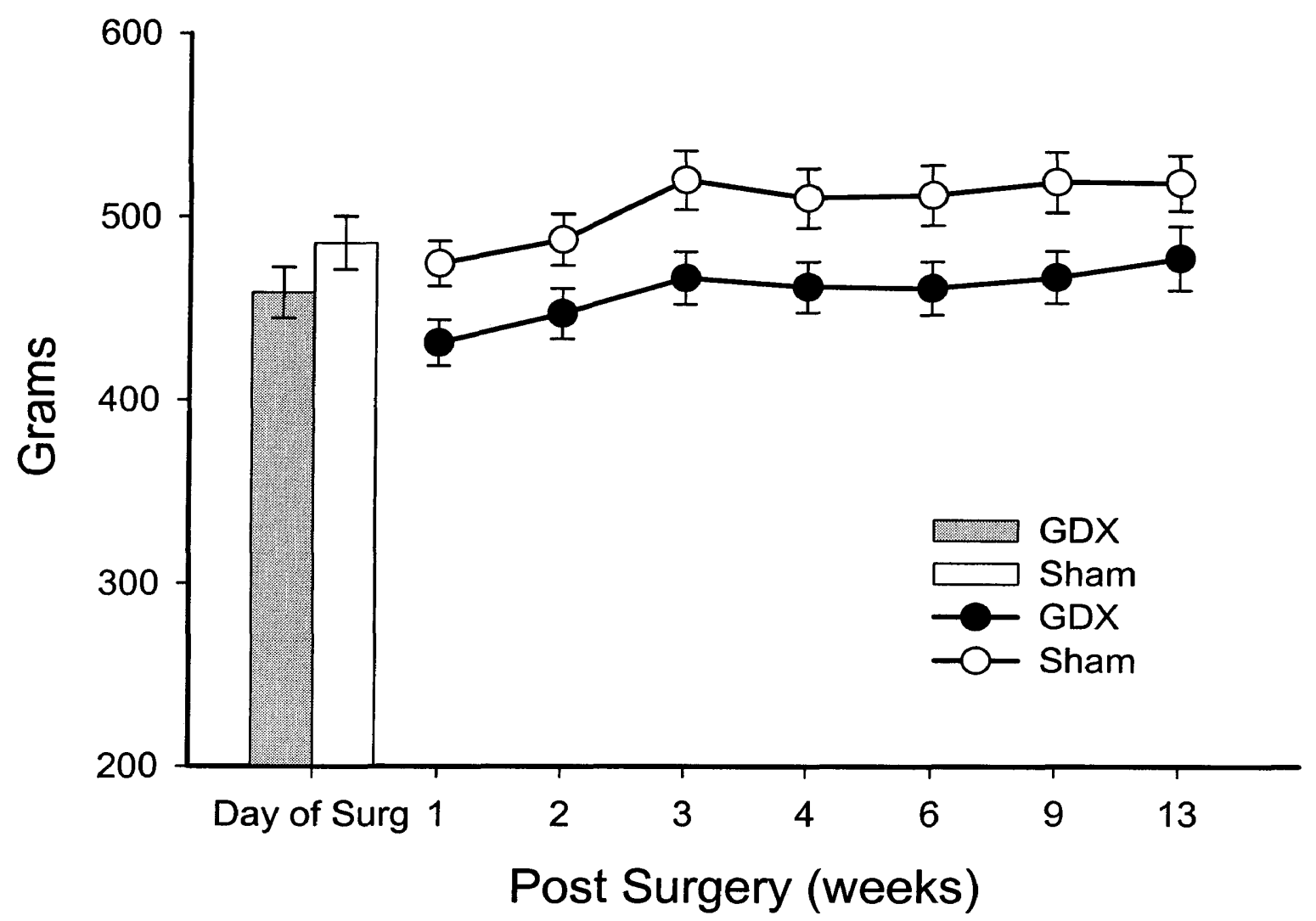

Average weights by group. GDX and Sham animals weighed similarly prior to surgery.

Post-surgery, GDX animals consistently weighed less than GDX animals. 


\section{FIGURE 2.}

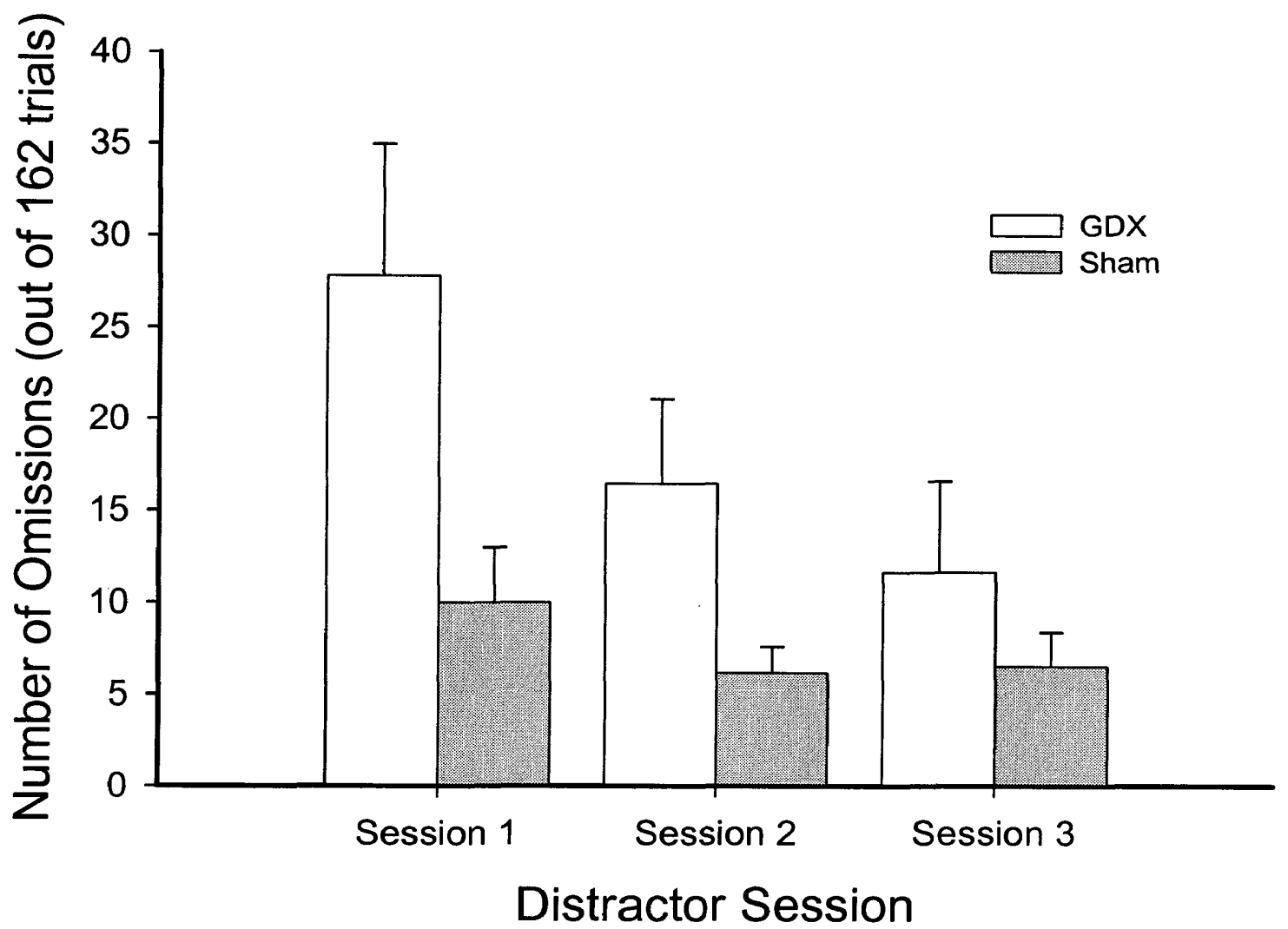

Omissions for distractor task sessions. The GDX group exhibited drastically increased omissions when tested with a visual distractor (flashing house light) compared to the Sham group. 
FIGURE 3

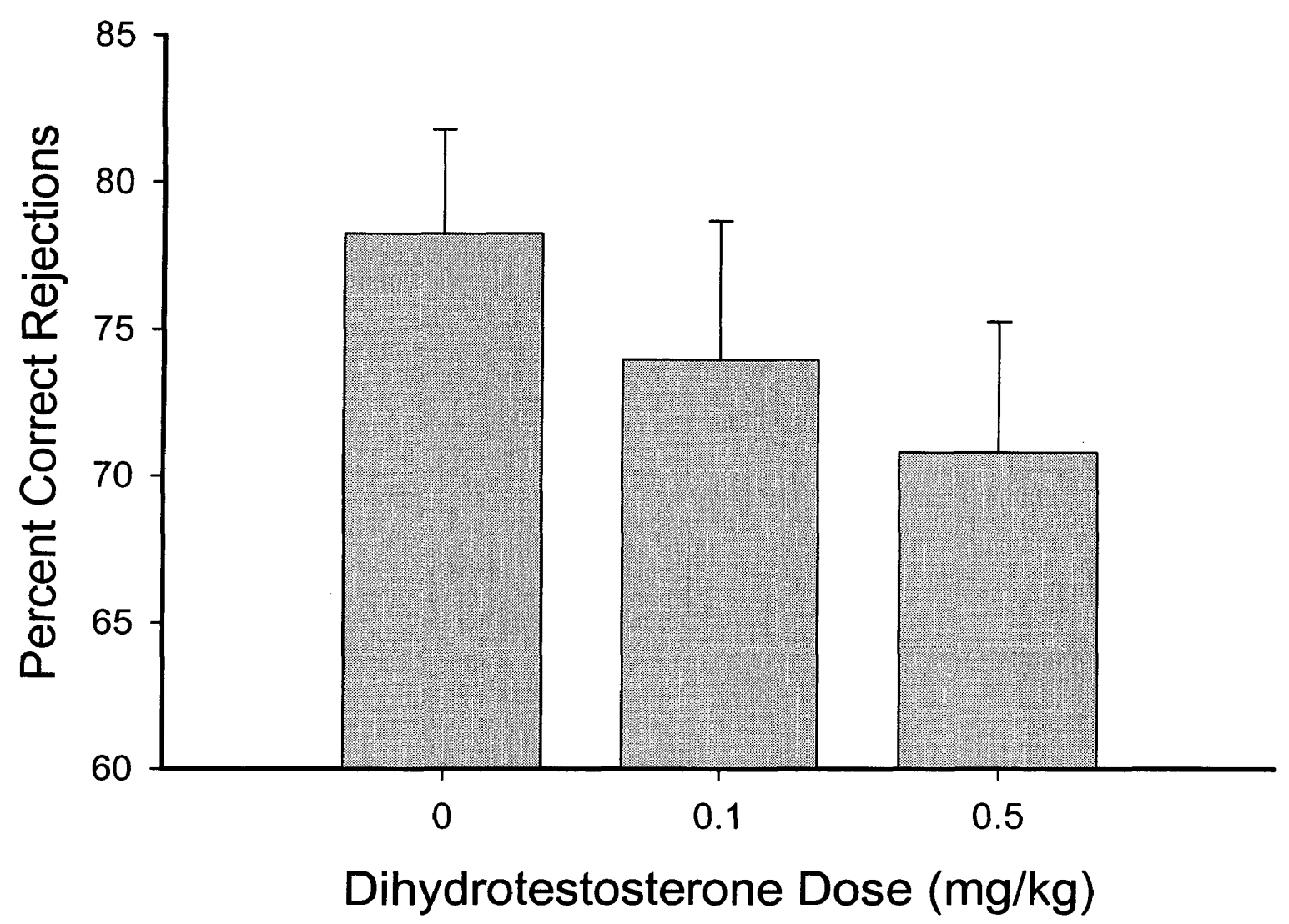

Percent correct rejections for each dose of DHT for distractor sessions only.

Administration of androgens decreased correct rejection accuracy during the distractor task. 
FIGURE 4

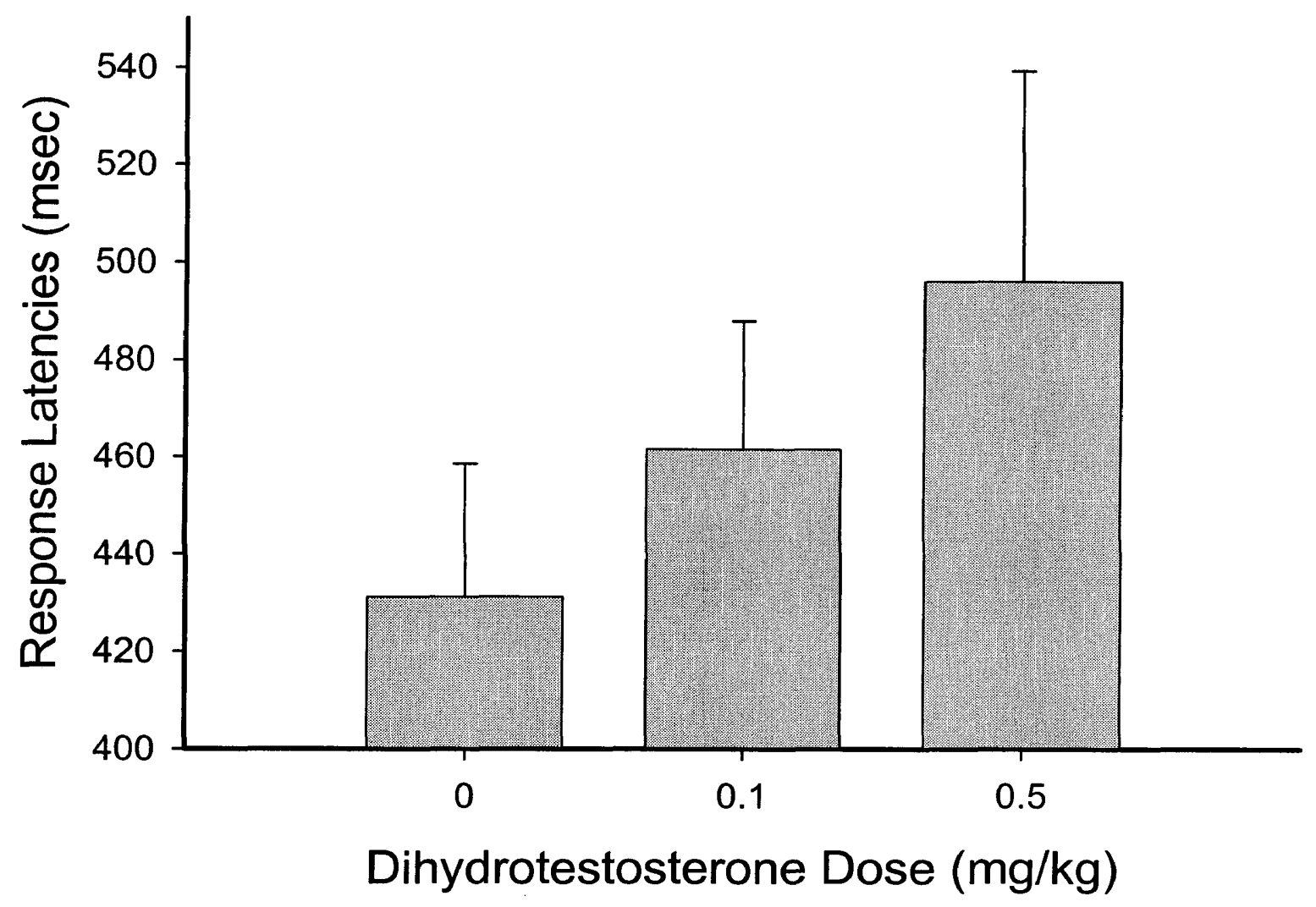

Response latencies for each dose of DHT for distractor sessions. During the distractor task, androgen administration increased response latencies. 


\section{FIGURE 5}

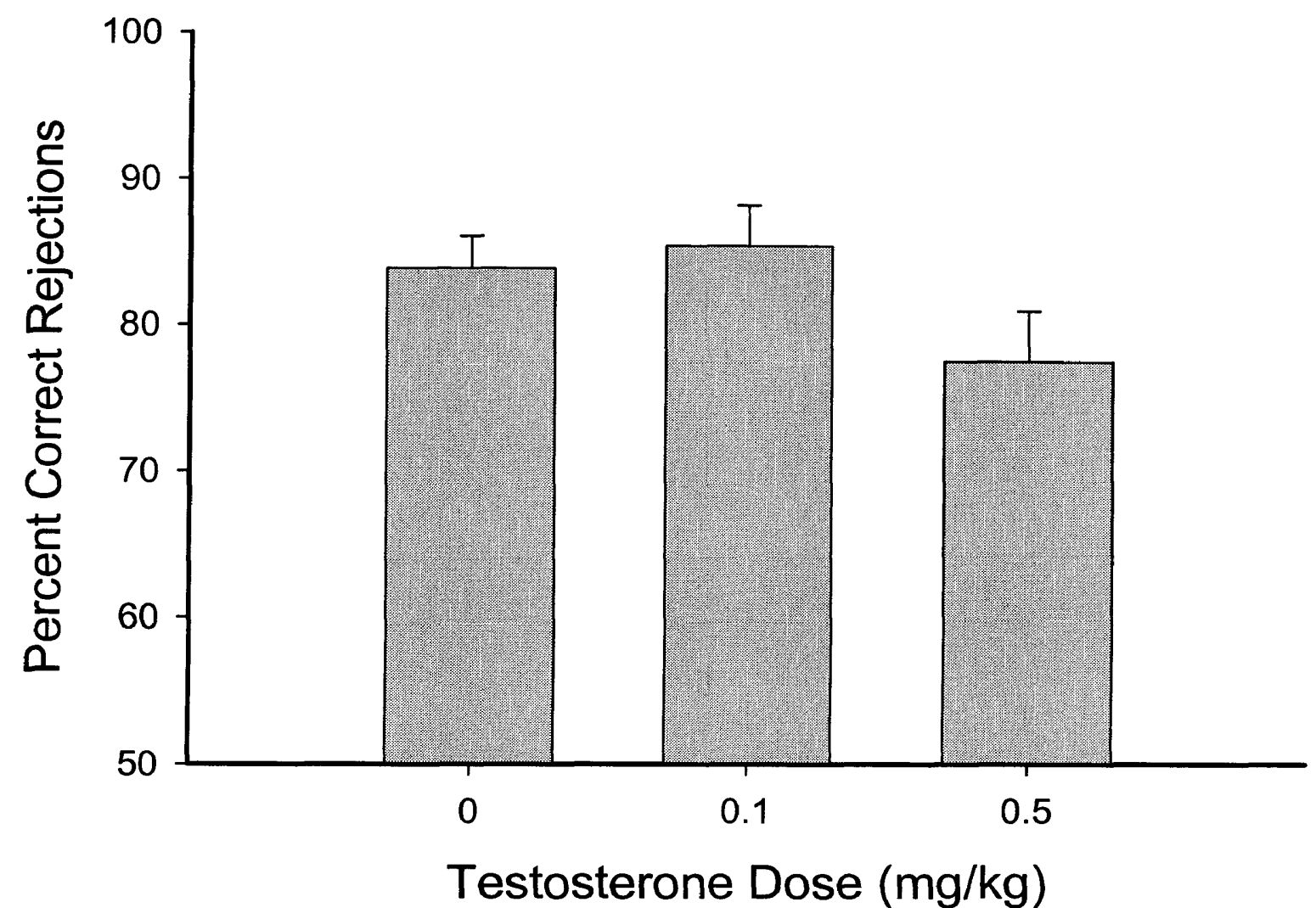

Correct rejection percentage for each dose of testosterone averaged across both distractor and standard task sessions. Administration of the high dose of androgens significantly reduced correct rejection accuracy. 


\section{FIGURE 6}

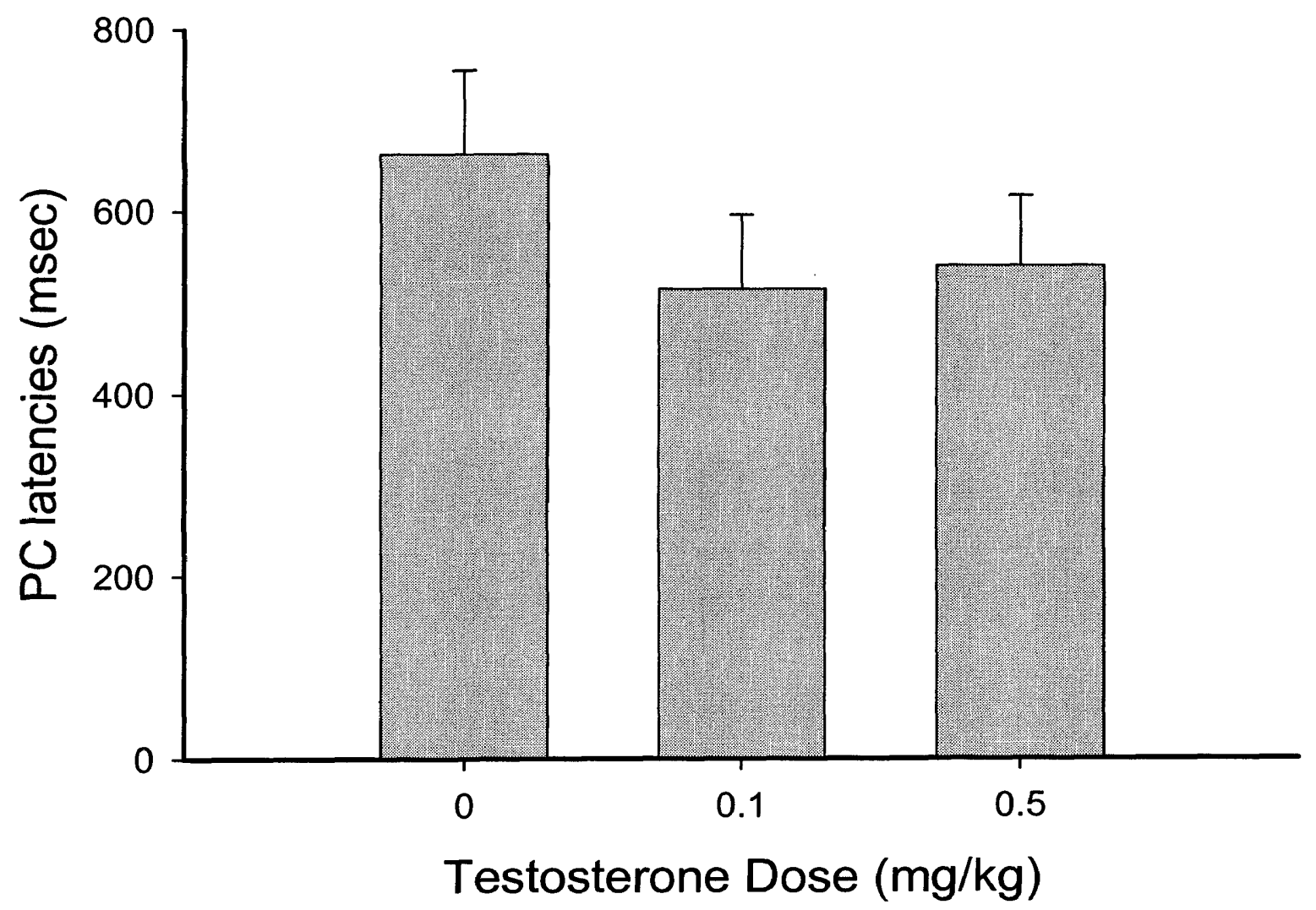

PC latencies for each dose of $\mathrm{T}$ averaged across the standard and distractor tasks. During the task, androgen administration reduced PC. 


\section{REFERENCES}

Adler, A., Vescovo, P., Robinson, J. K. \& Kritzer, M. F. (1999). Gonadectomy in adult life increases tyrosine hydroxylase immunoreactivity in the prefrontal cortex and decreases open field activity in male rats. Neuroscience, 89, 939-959.

Aikey, J. L., Nyby, J. G., Anmuth, D. M. \& James, P. J. (2002). Testosterone rapidly reduces anxiety in male house mice (mus musculus). Hormones and Behavior, 42, 448-460.

Aleman, A., Bronk, E., Kessels, R. P. C., Koppeschaar, H. P. F. \& van Honk, J. (2004). A single administration of testosterone improves visuospatial ability in young women. Psychoneuroendocrinology, 29, 612-617.

Allen, L. S. \& Gorski, R. A. (1991). Sexual dimorphism of the anterior commissure and massa intermedia of the human brain. Journal of Neuroscience, 9, 467-502.

Almeida, O. P., Waterreus, A., Spry, N., Flicker, L. \& Martins, R. N. (2004). One year follow-up study of the association between chemical castration, sex hormones, beta-amyloid, memory and depression in men. Psychoneuroendocrinology, 29, $1071-1081$.

Arnold, H. M., Burk, J. A., Hodgson, E. M., Sarter, M. \& Bruno, J. P. (2002). Differential cortical acetylcholine release in rats performing a sustained attention task versus behavioral control tasks that do not explicitly tax attention. Neuroscience, 114 , 451-460.

Ashe, J. H., McKenna, T. M., Weinberger, N. M. (1989). Cholinergic modulation of frequency receptive fields in auditory cortex: II. Frequency-specific effects of 
anticholinesterase provides evidence for a modulatory action of endogenous Ach, Synapse, 4, 44-54.

Asture, R. S., Ortiz, M. L. \& Sutherland, R. J. (1998). A characterization of performance by men and women in a virtual Morris water task: a large and reliable sex difference. Behavioral Brain Research, 93, 185-90.

Balthazart, J., Foidart, A., \& Harada, N. (1990). Immunocytochemical localization of aromatase in the brain. Brain Research, 514, 327-333.

Bates, K. A., Harvey, A. R., Carruthers, M. \& Martins, R. N. (2005). Androgens, andropause and neurodegeneration: exploring the link between steroidogenesis, androgens and Alzheimer's disease. Cellular and Molecular Life Sciences, 62, 281-292.

Bimonte-Nelson, H. A., Singleton, R. S., Nelson, M. E., Eckman, C. B., Barber, J., Scott, T. Y., Granholm, A. E. (2003). Testosterone, but not nonaromatizable dihydrotestosterone, improves working memory and alters nerve growth factor levels in aged male rats. Experimental Neurology, 181, 301-312.

Book, A., S., Starzyk, K. B. \& Quinsey, V. L. (2001). The relationship between testosterone and aggression: a meta-analysis. Aggression and Violent Behavior, 6, 579-599.

Bradley, D. R., Wygant, C. R. (1998). Male and female differences in anxiety about statistics are not reflected in performance. Psychological Reports, 82, 245-246.

Burk, J. A. \& Sarter, M. (2001). Dissociation between the attentional functions mediated via basal forebrain cholinergic and GABAergic neurons. Neuroscience, 105, 899909. 
Bushnell, P. J., Oshiro, W. M. \& Padnos, B. K. (1997). Detection of visual signals by rats: effects of chlordiazepoxide and cholinergic and adrenergic drugs on sustained attention. Psychopharmacology, 134, 230-241.

Celotti, F., Negri-Cesi, P. \& Poletti, A. (1997). Steroid metabolism in the mammalian brain 5alpha-reduction and aromatization. Brain Research Bulletin, 44, 365-375.

Compagnone, N. A., Mellon, S.H. (1998). Dehydroepianrosterone: A potential signaling molecule for neocortical organization during development. Proceedings of the National Academy of Science, 95, 4678-4683.

Compagnone, N. A. \& Mellon, S. H. (2000). Neurosteroids: Biosynthesis and function of these novel neuromodulators. Frontiers in Neuroendocrinology, 21, 1-56.

Connor, C. E., Egeth, H. E. \& Steven, Y. (2004). Visual attention: Bottom-up versus topdown. Current Biology, 14, R850-R852.

D’Intino, G., Paradisi, M., Fernandez, M., Giuliani, A., Aloe, L., Giardino, L. \& Calza, L. (2005). Cognitive deficit associated with cholinergic and nerve growth factor down-regulation in experimental allergic encephalomyelitis in rats. Proceedings of the National Academy of Science, 102, 3070-3075

Driscoll, I., Hamilton, D. A., Yeo, R. A., Brooks, W. M., \& Sutherland, R. J. (2005). Virtual navigation in humans: the impact of age, sex, and hormones on place learning. Hormones and Behavior, 47, 326-335.

Edinger, K. L., Lee, B. \& Frye, C. A. (2004). Mnemonic effects of testosterone and its $5 \alpha$-reduced metabolites in the conditioned fear and inhibitory avoidance tasks. Pharmacology Biochemistry and Behavior, 78, 559-568. 
Everitt, B. J. \& Robbins, T. W. (1997). Central cholinergic systems and cognition. Annual Review of Psychology, 48, 649-684.

Fahey, J.M., Lindquist, D.G., Pritchard, G.A., Miller, L.G. 1995. Pregnenolone sulfate potentiation of NMDA-mediated increases in intracellular calcium in cultured chick cortical neurons. Brain Research, 668, 183-188.

Fillit, H., Weinreb, H., Cholst, I., Luine, V., McEwen, B., Amador, R., \& Zabriskie, J. (1986). Observation in a preliminary open trial of estradiol therapy for senile dementia - Alzheimer's type. Psychoneuroendocrinology, 11, 337-345.

Frick, K. M., Burlingame, L. A., Arters, J. A., Berger-Sweeney, J. (2000). Reference memory, anxiety and estrous cyclicity in C57BL/6NIA mice are affected by age and sex. Neuroscience, 95, 293-307.

Frye, C. A. \& Edinger, K. L. (2004). Testosterone's metabolism in the hippocampus may mediate its anti-anxiety effects in male rats. Pharmacology Biochemistry and Behavior, 78, 473-481.

Frye, C. A. \& Seliga, A. M. (2001). Testosterone increases analgesia, anxiolysis, and cognitive performance of male rats. Cognitive, Affective, \& Behavioral Neuroscience, 1, 371-381.

Gill, T. M., Sarter, M. \& Givens, B. (2000). Sustained visual attention performanceassociated prefrontal neuronal activity: evidence for cholinergic modulation. Journal of Neuroscience, 20, 4745-4757.

Goodman, Y., Bruce, A. J., Cheng, B., \& Mattson, M. (1996). Estrogens attenuate and corticosterone exacerbates excitotoxicity, oxidative injury, and amyloid $\beta$-peptide toxicity in hippocampal neurons. Journal of Neuroscience, 66, 1836-1844. 
Gouras, G. K., XGross, R. S., Greenfield, J. P., Hai, B., Wang, R., Greengard, P. (1999). Testosterone reduces neuronal secretion of Alzheimer's $\beta$-amyloid peptides. Proceedings of the national academy of sciences, 97, 1202-1205.

Harrison, N. L., \& Simmonds, M. A. (1984). Modulation of GABA receptor complex by a steroid anesthetic, Brain Research, 323, 284-293.

Heideman, P. D., Bierl, C. K. \& Galvez, M. E. (2000). Inhibition of reproductive maturation and somatic growth of Fischer 344 rats by photoperiods shorter than L14:D10 and gradually decreasing photoperiod. Biology of Reproduction, 63, $1535-1540$.

Heideman, P. D., Bierl, C. K. \& Sylvester, C. J. (2001). Photoresponsive Fischer 344 rats are reproductively inhibited by melatonin and differ in 2-[1251] iodomelatonin binding from nonphotoresponsive Sprague Dawley rats. Journal of Neuroendocrinology, 13, 223-232.

Herlitz A, Airaksinen E, \& Nordstrom E. (1999). Sex differences in episodic memory: the impact of verbal and visuospatial ability. Neuropsychology, 13, 590-597.

Hull, E., Bitran, D., Pehek, E., Holmes, G., Warner, R., Band, L. \& Clemens, L. (1988). Brain localization of cholinergic influences on male sexual behavior in rats: agonists. Pharmacological \& Biochemical Behavior, 31:169-174.

Ishunina, T. A., Fisser, B., \& Swaab, D. F. (2002). Sex differences in androgen receptor immunoreactivity in basal forebrain nuclei of elderly and Alzheimer patients. Experimental Neurology, 176, 122-132.

Janowsky, J. S., Oviatt, S. K. \& Orwell, E. S. (1994). Testosterone influences spatial cognition in older men. Behavioral Neuroscience, 108, 325-332. 
Jentsch, J. D. \& Taylor, J. R. (2003). Sex-related differences in spatial divided attention and motor impulsivity in rats. Behavioral Neuroscience, 117, 76-83.

Kang, H. Y., Tsai, M. Y., Chang, C., \& Huang, K. E. (2003). Mechanisms and clinical relevance of androgens and androgen receptor actions. Chang Gung Medical Journal, 26, 388-402.

Kasa, P.,Rakonczay, Guyla, K. (1997). The Cholinergic System in Alzheimer's Disease. Progress in Neurobiology, 52, 511-535.

Kozak, R., Bruno, J. P. \& Sarter, M. (2005). Augmented prefrontal acetylcholine release during challenged attentional performance. Cerebral Cortex, Advance Access published on March 23, 2005.

Lawrence, A. D. \& Sahakian, B. J. (1998). The Cognitive Psychopharmacology of Alzheimer's Disease: Focus on Cholinergic Systems, Neurochemical Research, 23(5), 787-794.

Lewin C., Wolgers G. \& Herlitz A. (2001). Sex differences favoring women in verbal but not in visuospatial episodic memory. Neuropsychology, 15, 165-173.

Maruff, P., Hay, D., Malone, V., Currie, J. (1995) Asymmetries in the covert orienting of visual spatial attention in schizophrenia. Neuropsychologia, 33, 1205-1223.

MacLusky, N. J., Hajszan, T. \& Leranth, C. (2004). Effects of dehydroepiandrosterone and flutamide on hippocampal CA1 spine synapse density in male and female rats: implications for the role of androgens in maintenance of hippocampal structure. Endocrinology, 145, 4154-4161.

Mazur, A. \& Booth, A. (1998). Testosterone and dominance in men. Behavioral and Brain Sciences, 21, 353-397. 
McGaughy, J., Kaiser, T., \& Sarter, M. (1996). Behavioral vigilance following infusions of 192 IgG-saporin into the basal forebrain: Selectivity of the behavioral impairment and relation to cortical AChE-positive fiber density. Behavioral Neuroscience, 110(2), 247-265.

McGaughy, J. \& Sarter, M. (1995). Behavioral vigilance in rats: task validation and effects of age, amphetamine, and benzodiazepine receptor ligands. Psychopharmacology, 117, 340-357.

McIntyre, K. L., Porter, D. M. \& Henderson, L. P. (2002) Anabolic androgenic steroids induce age-, sex-, and dose dependent changes in GABAA receptor subunit mRNAs in the mouse forebrain. Neuropharmacology, 43, 634-645.

Meethal S. V. \& Atwood, C. S. (2005). The role of hypothalamic-pituitary-gonadal hormones in the structure and functioning of the brain. Cellular and molecular life sciences, 62, 257-270.

Mellon, S. H., Griffin, L. D., Compagnone, N. A. (2001) Biosynthesis and action of neurosteroids. Brain Research Reviews, 37, 3-12.

Mercado, E., Bao, S., Orduna, I., Gluck, M. A., Merzenich, M. M. (2001). Basal forebrain stimulation changes cortical sensitivities to complex sound, NeuroReport, 12, 2283-2287.

Mesulam, M. M. (1995). Structure and function of cholinergic pathways in the cerebral cortex, limbic system, basal ganglia, and thalamus of the human brain. In Bloom F. E. \& Kupfer, D. J. (Eds.) Psychopharmacology: The Fourth Generation of Progress. New York: Raven Press Ltd, 135-146. 
Mirsky, A. F., Anthony, B. J., Duncan, C. C., Ahearn, M. B., \& Kellam, S. G. (1991). Analysis of the elements of attention: A neuropsychological approach. Neuropsychology Review, 2(2), 109-145.

Mohapel, P., Leanzab, G., Kokaiaa, M., Lindvalla, O. (2005). Forebrain acetylcholine regulates adult hippocampal neurogenesis and learning. Neurobiology of Aging, $26,939-946$

Morris, J. A., Jordan, C. L. \& Breedlove, S. M. (2004). Sexual differentiation of the vertebrate nervous system. Nature Neuroscience, 7, 1034-1039.

Murphy, P. C. \& Sillito, A. M. (1991). Cholinergic enhancement of direction selectivity in the visual cortex of the cat, Neuroscience, 40, 13-20.

Naghdi, N., Majlessi, N., \& Bozorgmehr, T. (2004). The effect of intrahppocampal injection of testosterone enanthate (an androgen receptor agonist) and anisomycin (protein synthesis inhibitor) on spatil learning and memory in adult, male rats. Behavioural Brain Research, 156, 263-268.

Nakamura, N., Fujita, H. \& Kawata, M. (2002). Effects of gonadectomy on immunoreactivity for choline acetyltransferase in the cortex, hippocampus, and basal forebrain of adult male rats. Neuroscience, 109, 473-485.

Pashler, H. E. (1993). The Psychology of Attention. Massachusetts: MIT Press

Penschuck, S., Chen-Bee, C. H., Prakash, N., Frostig, R. D. (2002). In vivo modulation of a cortical functional sensory representation shortly after topical cholinergic agent application. Journal of Comparative Neurology, 452, 38-50.

Peterson, S. E., Fox, P. T., Miezin, F. M., Raichle, M. E. (1988). Modulation of cortical visual responses by direction of spatial attention measured by PET. Assoc. Res. 
Vision Opthal., p. 22 (Abstr.)

Phillips, S. M. \& Sherwin, B. B. (1992a). Effects of estrogen on memory function in surgically menopausal women. Psycholoneuroendocrinology 17(5), 485-495.

Phillips, S. M., \& Sherwin, B. B. (1992b). Variations in memory function and sex steroid hormones across the menstrual cycle. Psycholoneuroendocrinology 17(5), 497506.

Plassart-Schiess, E., Baulieu, E. (2001). Neurosteroids: recent findings. Brain Research Reviews, 37, 133-140.

Posner M. I. \& Peterson, S. E. (1990). The attention system of the human brain. Annual Review of Neuroscience, 13, 25-42.

Retana-Marquez, S., Dominguez Salazar, E., \& Velazquez-Moctezuma, J. (1993). Muscarinic and nicotinic influences on masculine sexual behavior: effects of oxotremorine, scopolamine, and nicotine. Pharmacology Biochemistry and Behavior, 44, 913-917.

Rhodes, M. E. \& Frye, C. A. (2004). Androgens in the hippocampus can alter, and be altered by ictal activity. Pharmacology Biochemistry and Behavior, 78, 483-493.

Rogers, J. L. \& Kesner, R. P. (2003). Cholinergic modulation of the hippocampus during encoding and retrieval. Neurobiology of Learning and Memory, 80, 332-342.

Rizk, A., Robertson, J. \& Raber, J. (2005). Behavioral performance of $t f m$ mice supports the beneficial role of androgen receptors in spatial learning and memory. Brain Research, 1034, 132-138.

Robbins, T. W., Everitt, B. J., Martson, H. M., Wilkinson, J., Jones G. H. \& Page K. J. (1989). Comparative effects of ibotenic acid and quisqualic acid-induced lesions 
of the subtantia innominata on attentional function in the rat: further implications for the role of the cholinergic neurons of the nucleus basalis in cognitive processes. Behavioral Brain Research, 35(3), 221-240.

Rosellini, R. A., Svare, B. B., Rhodes, M. E. \& Frye, C. A. (2001). The testosterone metabolite and neurosteroid $3 \alpha$-androstanediol may mediate the effects of testosterone on conditioned place preference. Brain Research Reviews, 37, 162171.

Sarter, M., Bruno, J. P. (1997). Cognitive functions of cortical acetylcholine: toward a unifying hypothesis. Brain Research Reviews, 23, 146-160.

Sarter, M., Bruno, J. P., \& Givens, B. (2003). Attentional functions of cortical cholinergic inputs: What does it mean for learning and memory? Neurobiology of Learning and Memory, 80, 245-256.

Sarter, M., Givens, B. \& Bruno, J. P. (2001). The cognitive neuroscience of sustained attention: where top-down meets bottom-up. Brain Research Reviews, 35, 146160.

Sarter, M., Hasselmo, M. E., Bruno, J. P. \& Givens, B. (2005). Unraveling the attentional functions of cortical cholinergic inputs: interactions between signal-driven and cognitive modulation of signal detection. Brain Research Reviews, 48, 98-111.

Sarter, M. \& Parikh, V. (2005). Choline transporters cholinergic transmission and cognition. Nature Neuroscience Reviews, 6, 48-56.

Swaab, D. F. \& Fliers E., (1985). A sexually dimorphic nucleus in the human brain. Science, 228, 1112-1115. 
Turchi, J. \& Sarter, M. (1997). Cortical acetylcholine and processing capacity: effects of cortical cholinergic deafferentation on crossmodel divided attention in rats. Cognitive Brain Research, 6, 147-158.

Tremblay, N., Warren, R. A., \& Dykes, R. W. (1990). Electrophysiological studies of acetylcholine and the role of the basal forebrain in the somatosensory cortex of the cat. II. Cortical neurons excited by somatic stimuli. Journal of Neurophysiology, 64, 1212-1222.

Voyer, D., Voyer, S. \& Bryden, M. M. (1995). Magnitude of sex differences in spatial abilities: a meta-analysis ad consideration of critical variables. Psychological Bulletin 117, 250-270.

Weaver, C. E., Marek, P., Park-Chung, M., Tam, S. W. \& Farb, D. H. (1997). Neuroprotective activity of a new class of steroidal inhibitors of the $N$-methyl-Dasparate receptor. Proceedings of the National Academy of Sciences, 94, 1045010454.

Weschler, D. A. (1958). The measurement and appraisal of adult intelligence. Baltimore: Williams \& Wilkins.

Williams, C. L. \& Meck, W. H. (1991). The organizational effects of gonadal steroids on sexually dimorphic spatial ability. Psychoneuroendocrinolog,y 16, 155-176.

Yang, P., Jones, B. L., \& Henderson, L. P. (2002) Mechanisms of anabolic androgenic steroid modulation of alpha(1)beta(3)gamma(2L) GABA(A) receptors. Neuropharmacology, 43, 619-633. 
Androgens and Attention 59

Zwain, I. H., Yen, S. S. C. (1999) .Neurosteroidogenesis in astrocytes, oligodenrocytes, and neurons of cerebral cortex of rat brain. Endocrinology, 140 (1999) 38433852. 


\section{VITA}

\section{$\underline{\text { Ryan Taylor Johnson }}$}

Ryan Taylor Johnson was born in Knoxville, Tennessee on February 5, 1979. He graduated from Farragut High School in June 1997 and went on to graduate cum laude from the University of Tennessee Knoxville in 2002 with a B.A. in Psychology. In August 2003, Ryan entered the College of William and Mary as a graduate student in the Department of Psychology. Ryan earned his Masters of Arts in June of 2005, and will be entering the Michigan State University Neuroscience program in the fall of 2005 to begin his doctoral studies. 